\title{
A Global Climatology of Extratropical Transition. Part I: Characteristics across Basins 0
}

\author{
MELANIE BIELI \\ Department of Applied Physics and Applied Mathematics, Columbia University, New York, New York \\ SuZANA J. CAMARGO \\ Lamont-Doherty Earth Observatory, Columbia University, Palisades, New York
}

ADAM H. SOBEL

Department of Applied Physics and Applied Mathematics, Columbia University, and Lamont-Doherty Earth Observatory, Columbia University, Palisades, New York

JENNI L. EVANS

Department of Meteorology and Atmospheric Science, The Pennsylvania State University, University Park, Pennsylvania

TIMOTHY HALL

NASA Goddard Institute for Space Studies, New York, New York

(Manuscript received 2 August 2017, in final form 29 January 2019)

\begin{abstract}
The authors present a global climatology of tropical cyclones (TCs) that undergo extratropical transition (ET). ET is objectively defined based on a TC's trajectory through the cyclone phase space (CPS), which is calculated using storm tracks from 1979-2017 best track data and geopotential height fields from reanalysis datasets. Two reanalyses are used and compared for this purpose, the Japanese 55-yr Reanalysis and the ECMWF interim reanalysis. The results are used to study the seasonal and geographical distributions of storms undergoing ET and interbasin differences in the statistics of ET occurrence. About $50 \%$ of all TCs in the North Atlantic and the western North Pacific undergo ET. In the Southern Hemisphere, ET fractions range from about $20 \%$ in the south Indian Ocean and the Australian region to $45 \%$ in the South Pacific. In the majority of ETs, TCs become thermally asymmetric before forming a cold core. However, a substantial fraction of TCs take the reverse pathway, developing a cold core before becoming thermally asymmetric. This pathway is most common in the eastern North Pacific and the North Atlantic. Different ET pathways can be linked to different geographical trajectories and environmental settings. In ETs over warmer sea surface temperatures, TCs tend to lose their thermal symmetry while still maintaining a warm core. Landfalls by TCs undergoing ET occur 3-4 times per year in the North Atlantic and 7-10 times per year in the western North Pacific, while coastal regions in the Australian region are affected once every 1-2 years.
\end{abstract}

\section{Introduction}

Toward the end of their lifetimes, tropical cyclones (TCs) often undergo a process called extratropical transition (ET), in which they change their physical structure and

Supplemental information related to this paper is available at the Journals Online website: https://doi.org/10.1175/JCLI-D-17-0518.1.s1.

Corresponding author: Melanie Bieli, mb4036@columbia.edu develop characteristics typical of extratropical cyclones. ET occurs as a TC moves into higher latitudes and encounters cooler sea surface temperatures and stronger vertical wind shear (Jones et al. 2003; Evans et al. 2017). The baroclinic environment sets the stage for the transition of the TC: As colder, drier air intrudes into the warm core, the storm loses its radial symmetry and begins to tilt toward the cold upper-level air. Eventually the TC becomes a cold-core system with asymmetric, frontal structure, completing its transition to an extratropical cyclone. 
During ET, a storm may reintensify as it starts to tap baroclinic energy in addition to the energy source residing in the thermodynamic disequilibrium between the atmosphere and the underlying ocean. Often the system also accelerates its forward motion and produces intense precipitation, strong winds, surge, and surface water waves, posing a serious threat to coastal regions and maritime activities (Jones et al. 2003). In particular, tropical systems that reintensify after ET in the North Atlantic can constitute a hazard for Canada and/or northwest Europe; for example, the transitioning Hurricane Igor (2010) caused severe flooding in Newfoundland (Masson 2014), and the extratropical system that developed from Hurricane Lili (1996) was responsible for seven deaths and substantial economic losses in Europe (Agustí-Panareda et al. 2005). In October 2017, Hurricane Ophelia became the easternmost Atlantic major hurricane in recorded history and transformed into an extratropical cyclone that wreaked havoc on Ireland and Great Britain (Roseli et al. 2017).

Around the turn of the millennium, the increasing awareness that the nature of a storm can change over the course of its life cycle sparked case studies of individual transitions (e.g., Thorncroft and Jones 2000; Atallah and Bosart 2003; McTaggart-Cowan et al. 2003) as well as on basin-specific climatologies (e.g., Foley and Hanstrum 1994; Klein et al. 2000; Hart and Evans 2001; Sinclair 2002). However, advances in research were hindered by the lack of an objective definition of ET. This gap was filled by the cyclone phase space (CPS) framework proposed by Hart (2003), whose effectiveness for the study of ET was first demonstrated by Evans and Hart (2003). Since then, the CPS has become well established and has gained acceptance at operational forecast centers (Evans et al. 2017). The CPS allows for automated and objective detection of ET in large sets of storms and hence paved the way for statistical approaches to describe the phenomenon. This motivated more recent ET climatologies in various ocean basins (e.g., Kitabatake 2011; Wood and Ritchie 2014).

Past climatologies of ET have mostly focused on single ocean basins and are based on a variety of datasets, methodologies, and time periods. This makes their results difficult to compare. For example, using the ET designation in the Japanese Meteorological Agency's best track dataset, Kitabatake (2011) found that $49 \%$ of TCs in the western North Pacific undergo ET. In the same basin, Klein et al. (2000) obtained an ET fraction of $27 \%$ using satellite imagery to define ET. Different estimates also exist for other basins: $46 \%$ of North Atlantic storms were identified as ET storms in Hart and Evans (2001), compared to $68 \%$ in Studholme et al. (2015). The latter study also found that more than a third of TCs in the eastern North Pacific transition, whereas Wood and Ritchie (2014) obtained an ET fraction of 9\% in that basin. Studholme et al. (2015), who applied a combination of CPS and a $k$-means clustering to TCs tracked in reanalysis data, speculate that their higher fractions might be a consequence of longer tracks, which allow more time for ET to occur.

As illustrated by these examples, differences in data and methodology stand in the way of a better understanding of the ET variability between basins. The lack of a global perspective on ET has been pointed out by Evans et al. (2017) and provides the motivation for the study at hand: Using a consistent set of data, time period, and method, we present a global CPS-based climatology of ET that encompasses all major cyclone basins. Following up on this study, Bieli et al. (2019, hereafter Part II) explore the CPS-based definition of ET in further detail, by assessing its dependence on the underlying reanalysis dataset as well as its statistical performance in a comparison with the ETs defined by human forecasters.

\section{Data and methods}

\section{a. TC best track and reanalysis datasets}

The two basic ingredients for this analysis are global TC track data and geopotential height fields from reanalysis datasets. We use best track datasets from the National Hurricane Center (NHC) in the North Atlantic (NAT) and in the eastern North Pacific (ENP), from the Joint Typhoon Warning Center (JTWC) in the north Indian Ocean (NI), the Southern Hemisphere (SH), and the western North Pacific (WNP), and from the Japan Meteorological Agency (JMA) in the WNP. The reason for including the WNP best track archives of the JMA and the JTWC is that there are systematic, welldocumented differences between these two datasets (e.g., Song et al. 2010; Ying et al. 2011; Schreck et al. 2014). Within the SH, we distinguish the south Indian Ocean (SI), the Australian region (AUS), and the South Pacific (SP).

The best track data provide the position of the storm center, maximum wind speed, and the type of the storm as declared by the respective operational meteorological agencies. In the best track archives of the JTWC, the "storm type" records only start in 2004. In the ENP best track data, the NHC has been providing storm type labels since 1988. For our analysis, we consider TCs that occurred in the satellite era 1979-2017, excluding storms that never developed wind speeds greater than $33 \mathrm{kt}$ $\left(1 \mathrm{kt} \approx 0.51 \mathrm{~m} \mathrm{~s}^{-1}\right)$, that is, that remained at or below tropical depression intensity throughout their lifetime. 
TABLE 1. Definitions and acronyms of the ocean basins examined in this study, including their sources of best track datasets, number of storms, and peak seasons (ASO: August-October, JASO: July-October, JAS: July-September, OND: October-December, JFM: January-March, and DJF: December-February). The time period is 1979-2017 for all basins.

\begin{tabular}{llcccc}
\hline \multicolumn{1}{c}{ Basin } & Code & Source of best tracks & No. of Storms & Longitudes & Peak season \\
\hline North Atlantic & NAT & NHC & 481 & American coast to $30^{\circ} \mathrm{E}$ & ASO \\
Western North Pacific & WNP & JMA, JTWC & 994,1002 & $100^{\circ} \mathrm{E}-180^{\circ}$ & JASO \\
Eastern North Pacific & ENP & NHC & 656 & $180^{\circ}$ to American coast & JAS \\
North Indian Ocean & NI & JTWC & 188 & $30^{\circ}-100^{\circ} \mathrm{E}$ & OND \\
South Indian Ocean & SI & JTWC & 344 & $30^{\circ}-90^{\circ} \mathrm{E}$ & JFM \\
Australian region & AUS & JTWC & 389 & $90^{\circ}-160^{\circ} \mathrm{E}$ & JFM \\
South Pacific & SP & JTWC & 236 & $160^{\circ} \mathrm{E}-120^{\circ} \mathrm{W}$ & JFM \\
\hline
\end{tabular}

Table 1 highlights the key characteristics of the resulting set of storms and complements Fig. 1, which shows a subset of the storm tracks examined in this study, together with the boundaries of the ocean basins.

To examine the sensitivity of the results with respect to the reanalysis dataset considered, all calculations were performed on the Japanese 55-yr Reanalysis $\left(\right.$ JRA-55; $1.25^{\circ} \times 1.25^{\circ}$ ) released by the JMA (Kobayashi et al. 2015) as well as on the European Centre for Medium-Range Weather Forecasts' (ECMWF) interim reanalysis (ERA-Interim; $0.7^{\circ} \times 0.7^{\circ}$; Dee et al. 2011). Both datasets are considered state-of-the-art reanalyses and apply a four-dimensional variational data assimilation to provide dynamically consistent estimates of the state of the atmosphere. It is worth noting that the JRA-55 assimilation system uses artificial wind profile retrievals in the vicinity of TCs. Generated by synthetic dropwindsondes, the wind profile retrievals approximate the TC wind profile at the best track locations and are then processed like observed data (Hatsushika et al. 2006; Ebita et al. 2011). ERAInterim, on the other hand, does not assimilate any artificial TC information.
Schenkel and Hart (2012) found that there can be considerable position and intensity differences between the best track TCs and the corresponding TCs in the reanalysis, especially for weak storms in observationscarce regions. To gauge the effect of these possible mismatches, the best track positions were mapped to the closest sea level pressure minimum in the reanalysis within a $300-\mathrm{km}$ radius of that in the best track. However, these recentered tracks did not improve the performance of the CPS classification (as defined by the performance metrics used in Part II) and are therefore not included here.

\section{b. Indices of climate variability}

We use monthly sea surface temperature (SST) anomalies in the Niño-3.4 region (Barnston et al. 1997) provided by the Climate Prediction Center (CPC 2018) to define the phase of the El Niño-Southern Oscillation (ENSO) phenomenon. In each basin, years with El Niño and La Niña conditions are defined according to the value of the Niño-3.4 index averaged over the months of its peak season (Table 1). If this value reaches a threshold of $0.5(-0.5)$ and falls within a period of at

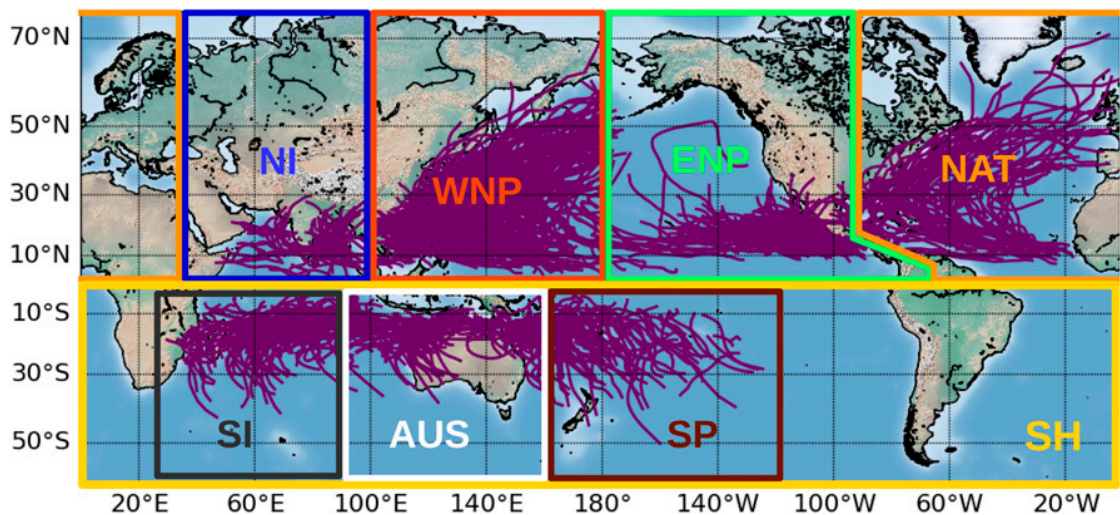

FIG. 1. Global best tracks of TCs from 1990 to 2000 (a subset of the 1979-2017 best tracks used in this study), and the boundaries of the domains examined in this study: North Atlantic (NAT), western North Pacific (WNP), eastern North Pacific (ENP), north Indian Ocean (NI), south Indian Ocean (SI), Australian region (AUS), and South Pacific (SP). 
least five consecutive overlapping 3-month intervals exceeding that threshold, a year is considered an El Niño (La Niña) year. Thus, the ENSO phase of a given year may differ between basins with different peak seasons.

The Atlantic meridional mode (AMM) and Pacific meridional mode (PMM) SST indices developed by Chiang and Vimont (2004) are the result of a maximum covariance analysis of tropical SSTs. Time series of monthly AMM and PMM indices are available from the NOAA Earth System Research Laboratory (NOAA ESRL 2018). The annual time series used to examine correlations with the occurrence of ET were obtained by taking the average over the peak season in each basin.

\section{c. Cyclone phase space}

We employ the CPS proposed by Hart (2003) to objectively identify storms that undergo ET. In the CPS framework, the physical structure of cyclones is described based on three parameters that can be computed from geopotential height fields: The $B$ parameter measures the asymmetry in the layer-mean temperature surrounding the cyclone, and two thermal wind $\left(V_{T}\right)$ parameters assess whether the cyclone has a warm or cold core structure in the upper $\left(-V_{T}^{U}\right)$ and lower $\left(-V_{T}^{L}\right)$ troposphere (with the convention of the minus sign, positive values correspond to warm cores). In this study, we treat all three parameters as dimensionless quantities that have been normalized by their units.

The $B$ parameter is computed by taking the difference between the average 900-600-hPa geopotential thickness to the right and to the left of the storm, in a radius of $500 \mathrm{~km}$ around the storm center:

$$
B=h\left(\left.\overline{Z_{600 \mathrm{hPa}}-Z_{900 \mathrm{hPa}}}\right|_{R}-\left.\overline{Z_{600 \mathrm{hPa}}-Z_{900 \mathrm{hPa}}}\right|_{L}\right),
$$

where $Z$ is geopotential height, $R$ indicates right relative to the storm motion, $L$ indicates left relative to the storm motion, and the overbar indicates the areal mean over a semicircle of radius $500 \mathrm{~km}$. The hemispheric parameter $h$ is 1 for the Northern Hemisphere and -1 for the Southern Hemisphere. Thermally symmetric storms will thus have $B$ values close to zero, while large $B$ values represent thermally asymmetric storms.

The parameters $-V_{T}^{L}$ and $-V_{T}^{U}$ evaluate the thermal wind in the 900-600-hPa layer and the $600-300-\mathrm{hPa}$ layer, respectively:

$$
\begin{gathered}
-V_{T}^{L}=\left.\frac{\partial \Delta Z}{\partial(\ln p)}\right|_{900 \mathrm{hPa}} ^{600 \mathrm{hPa}}, \\
-V_{T}^{U}=\left.\frac{\partial \Delta Z}{\partial(\ln p)}\right|_{600 \mathrm{hPa}} ^{300 \mathrm{hPa}} .
\end{gathered}
$$

They are computed by linear regression of $\Delta Z$, the difference in maximum and minimum geopotential height within $500 \mathrm{~km}$ of the storm's center, over seven pressure levels. The pressure levels range from 900 to $600 \mathrm{hPa}$ and from 600 to $300 \mathrm{hPa}$, in increments of $50 \mathrm{hPa}$. Positive values of $-V_{T}^{L}$ and $-V_{T}^{U}$ (weakening geostrophic wind with height) indicate the presence of a warm core in that layer, while strengthening winds with height lead to negative values and are associated with cold-cored systems.

Evans and Hart (2003) define the onset of ET as the time when the $B$ parameter first exceeds a value of 10 , while the drop of $-V_{T}^{L}$ below zero marks the end of the process. The two diagrams in Fig. 2 illustrate the idealized CPS trajectories of a storm whose ET starts with the loss of the thermal symmetry and ends with the formation of a cold core ( $B \rightarrow V_{T}$ transition). Alternatively, a TC can undergo ET by developing a cold core before losing its symmetry ( $V_{T} \rightarrow B$ transition), or by acquiring both characteristics at the same 6-hourly time step (direct transition). Thus, ET onset is defined here as the first time a TC is either asymmetric or has a cold core, and ET completion is when the second criterion is met.

For this study, no smoothing was applied to the CPS parameters, and building on the results of Part II, the original definition of ET has been modified with the purpose of maximizing the agreement with the ET cases in the best track datasets: We increased the $B$ threshold to 11 and required the cyclone to develop a cold-core structure throughout the $900-300-\mathrm{hPa}$ layer; that is, we required $-V_{T}^{U}$ as well as $-V_{T}^{L}$ to become negative. Evans and Hart (2003) argued that as the upper troposphere usually becomes cold prior to the lower troposphere, thermal wind in the lower troposphere provides a more stringent criterion on transition completion than the upper-tropospheric thermal wind, and hence they did not impose any condition on $-V_{T}^{U}$. The inclusion of the $-V_{T}^{U}$ criterion is further discussed in section $3 \mathrm{~b}$. In addition, ET onset was only declared if a storm had wind speeds of at least $33 \mathrm{kt}$, as some tropical depression-like systems or monsoonal troughs raise false alarms due to their asymmetric structure.

After computing the CPS parameters along all best tracks (once in JRA-55 and once in ERA-Interim), we applied the CPS criteria to diagnose each TC either as an "ET storm" (i.e., a storm that undergoes ET at some point in its lifetime) or as a "non-ET storm" (i.e., a storm that does not undergo ET).

\section{d. Clustering method}

We used the clustering method by Gaffney (2004) to separate TC tracks into different clusters. The method is described in detail in Gaffney et al. (2007) and has been 

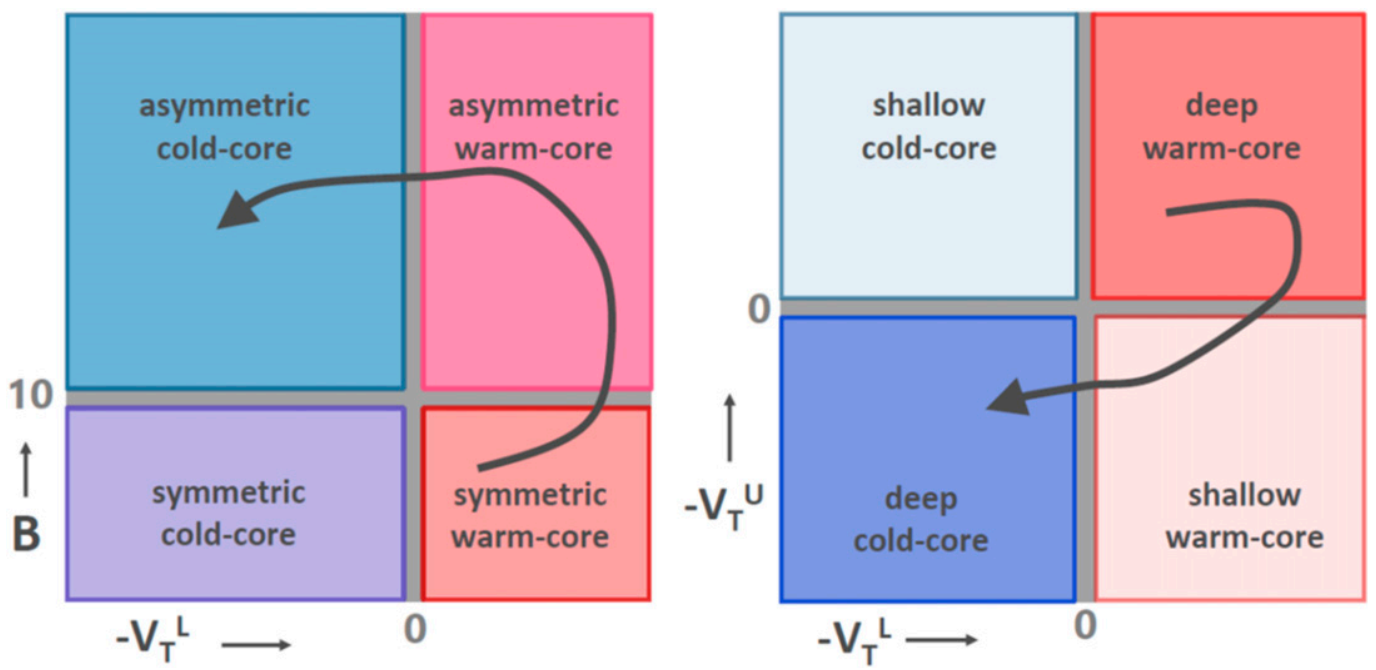

FIG. 2. Overview of the CPS proposed by Hart (2003), showing cross sections of (left) $B$ vs $-V_{T}^{L}$, and (right) $-V_{T}^{L}$ vs $-V_{T}^{L}$. The arrows trace out idealized paths of a storm undergoing ET, illustrating how its physical structure changes from symmetric warm core to asymmetric cold core in the left panel and from deep warm core to deep cold core in the right panel.

applied to cyclone tracks in various basins (e.g., Camargo et al. 2007b,c, 2008; Kossin et al. 2010; Ramsay et al. 2012; Boudreault et al. 2017). At its core is a polynomial regression mixture model that is used to fit the geographical shape of the TC tracks. Each track is assigned to one of $K$ different clusters, each of which represents a separate regression model with its own shape parameters. The number of clusters represents a compromise between maximizing the log-likelihood of the observed data given a specific cluster assignment, while using as few clusters as possible.

The clustering was performed on the best track datasets from the NHC for the NAT and the ENP, and on those from the JTWC for the SH, the NI, and the WNP. For consistency, following Camargo et al. $(2007 b, c)$, we performed the clustering in the WNP only once, using the JTWC best tracks, and then determined the cluster membership of the TCs in the JMA best tracks in the WNP by identifying them with their corresponding tracks in the JTWC best tracks.

\section{Results}

\section{a. CPS parameters and trajectories}

The CPS parameters calculated along the TC tracks are the building blocks of this global ET climatology and provide the starting point of our analysis. Boxplots of the CPS parameters for all 6-hourly time intervals and all storms (Fig. 3) show that the medians of both thermal wind parameters are positive, indicating the dominant presence of warm-cored storms in the dataset as a whole.
The distributions of the $B$ parameter are concentrated around zero, representing the fingerprint of thermally symmetric tropical storms. As we will show in section 3b, the long tails extending into the extratropical parameter ranges $\left(B>11,-V_{T}^{L}<0,-V_{T}^{U}<0\right)$ in the NAT and the WNP manifest themselves in high ET fractions in these two basins.

Given the thresholds for asymmetry and cold-core structure, all CPS trajectories of transitioning storms exhibit, by construction, some broad level of similarity. Within that possible range, though, individual trajectories of transitioning cyclones in the CPS are very diverse, demonstrating a wide range of structural evolutions. Apart from the high degree of interstorm variability, the CPS path for a given storm may also differ depending on which dataset was used to calculate the CPS parameters. Figure 4 illustrates this dependence using the example of Tropical Storm Earl (1992), whose trajectory in a $B$ vs $-V_{T}^{L}$ cross section of the CPS (Figs. 4a,b) looks markedly different for the two reanalyses used in this study. Earl does not undergo ET in JRA-55, while the ERAInterim trajectory depicts a full transition to an extratropical system (for reference, Earl also becomes extratropical in the NHC best track data).

At 0600 UTC 3 October (the third-to-last track point), Earl is clearly visible in the relative vorticity fields at $850 \mathrm{hPa}$ (Figs. 4c,d) of the two reanalyses, which feature a vortex centered northeast of Florida. The peak values are higher in ERA-Interim, but the differences in position and size of the storm in the two reanalyses are too small to explain the discrepancy in the CPS trajectories. 

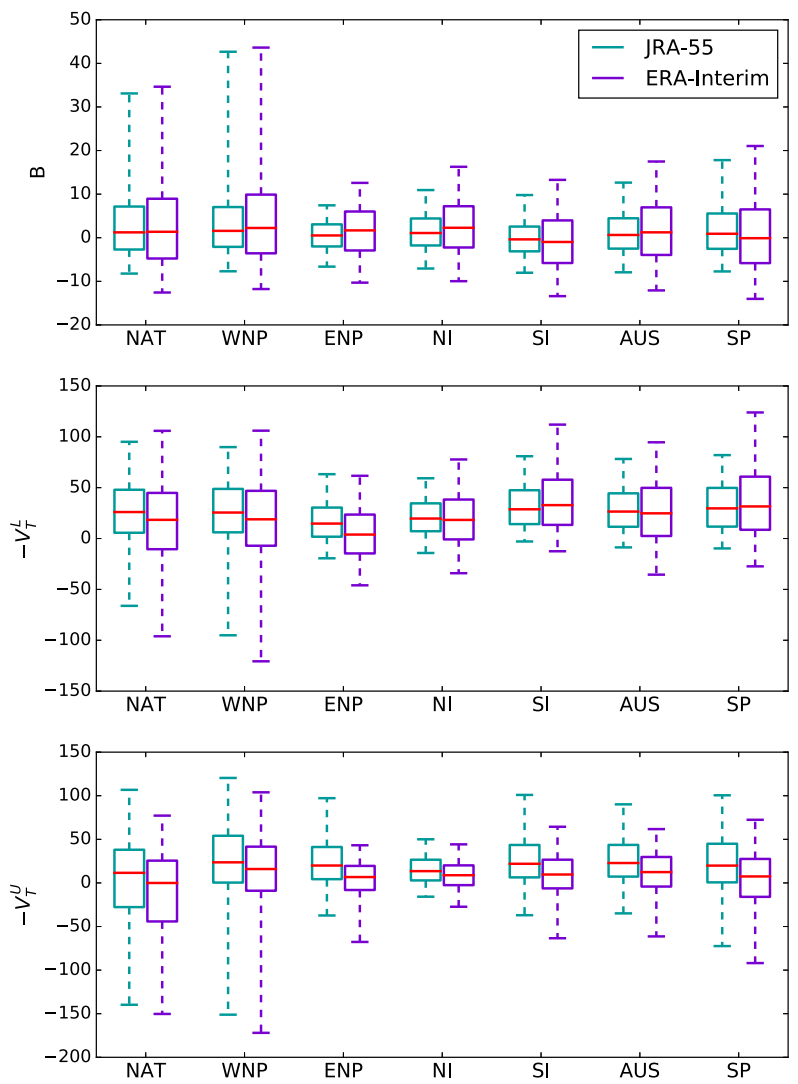

FIG. 3. Box-and-whisker plots for the CPS parameters, calculated in JRA-55 and ERA-Interim. The box extends from the lower to the upper quartile, with a red line at the median, and the whiskers extend from the 5 th to the 95 th percentile.

As expected from the $B$ vs $-V_{T}^{L}$ trajectory, the $\Delta Z$ profile (Fig. 4e) of JRA-55 decreases with height in the 900-600-hPa layer, indicating a warm core in the lower troposphere. This is consistent with the storm's position in the upper right "asymmetric warm-core" quadrant of the CPS. In contrast, the ERA-Interim profile shows increasing geostrophic wind (and thus a cold-core structure) throughout the 900-300-hPa layer; consequently, the storm is located in the upper left "extratropical" quadrant.

The following sections will show that such differences between JRA-55 and ERA-Interim are not only visible in individually selected storms but also in the climatological basin statistics.

\section{b. Fraction}

Figure 5 shows the global ET fractions computed using the CPS and those obtained from the best track labels. Note that the CPS-derived ET fractions in Fig. 5 refer to the time period for which best track labels are available (Table 1). An overview of all CPS-derived fractions for the entire time period 1979-2017 is given in Table 2.
There are several notable differences among ocean basins as well as between the two reanalysis datasets: According to the JMA and NHC best track data, $48 \%$ of the storms in the WNP and $44 \%$ of the storms in the NAT undergo ET. Compared to these two basins, ET is rare in the ENP and the NI $(1.8 \%$ and $2.7 \%$, respectively). The low ET fraction in the ENP is mostly the result of a strong subtropical ridge over southwestern North America, which exerts its influence over much of the hurricane season and tends to steer the cyclones westward away from land, keeping them in low latitudes (Wood and Ritchie 2014). In the NI, northward moving storms usually make landfall before reaching a sufficiently baroclinic environment to undergo transition. Of the SH basins, the SP (45\%) has a considerably higher ratio of ET storms than the SI $(27 \%)$ and the AUS (19\%).

The ERA-Interim fractions exceed the JRA-55 values and the observations in all basins, particularly in the ENP. This pattern is robust even when considering the sensitivity to various definitions of ET onset and ET completion (e.g., when varying the $-V_{T}^{L}$ and $-V_{T}^{U}$ thresholds from 0 to -10$)$. A two-sample, two-sided $t$ test confirms that all differences between the ET fractions of the two reanalyses shown in Fig. 5 are significant at the 0.95 confidence level. The $t$ test was performed using sample means and sample standard deviations obtained from repeatedly $(n=1000)$ computing the ET fractions on randomly sampled subsets (5 years) of storms.

ET fractions depend not only on the basin and the reanalysis dataset, but also on the best track archive: In the WNP, the percentage of storms undergoing ET in the JMA dataset exceeds that in the JTWC dataset by 4.6 percentage points (Fig. 5). The difference in the objective, CPS-based ET fractions is even greater, indicating that its primary reason lies in the tracks themselves rather than in different operational practices at the warning centers. Indeed, Fig. 6 reveals that the JMA best tracks extend farther northeast: Their average end position is $32^{\circ} \mathrm{N}, 139^{\circ} \mathrm{E}$ (standard deviation: $14^{\circ}, 29^{\circ}$ ), while the average JTWC best track ends at $28^{\circ} \mathrm{N}, 131^{\circ} \mathrm{E}$ (standard deviation: $10^{\circ}, 22^{\circ}$ ). Thus, the JMA continues more cyclone tracks into the midlatitude zone where ET tends to occur. As they cross the date line from west to east, the cyclones leave the area of responsibility of the JMA, and their tracks are discontinued.

Of all cyclones that undergo ET along the JMA best track but not along the JTWC best track, about $85 \%$ complete ET farther north than the latitude of the last JTWC track point. Given that the JMA labels are available over a longer time period and that the CPS classification of ET storms obtained from the JMA 
a)

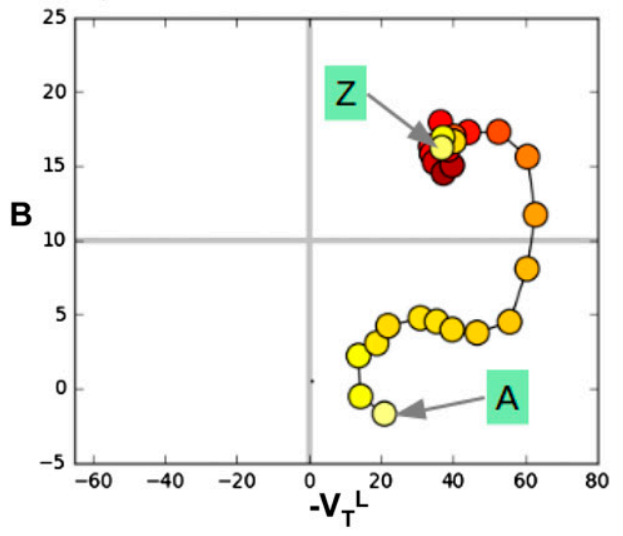

c)

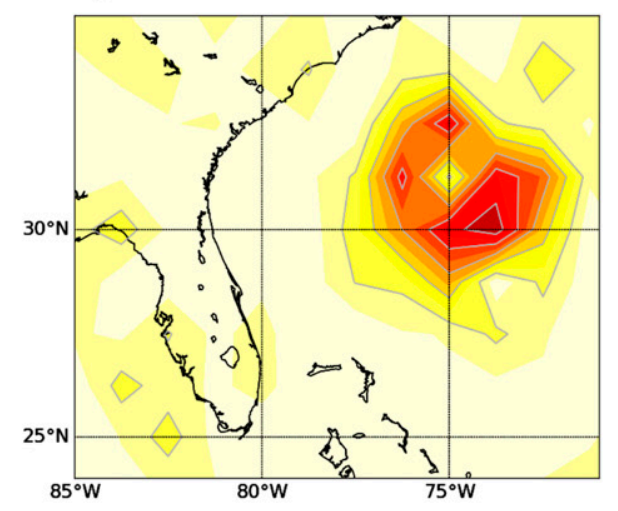

b)

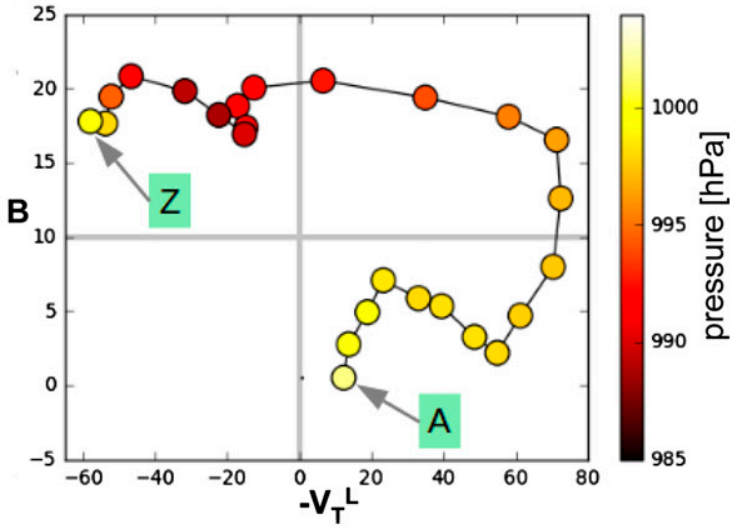

d)

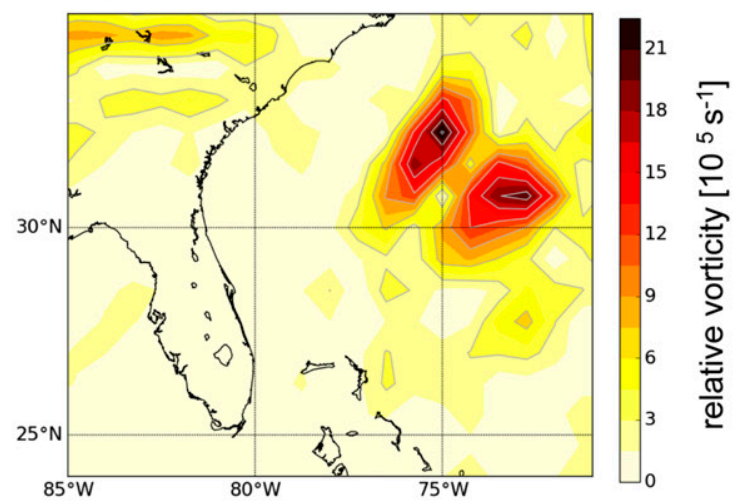

e)
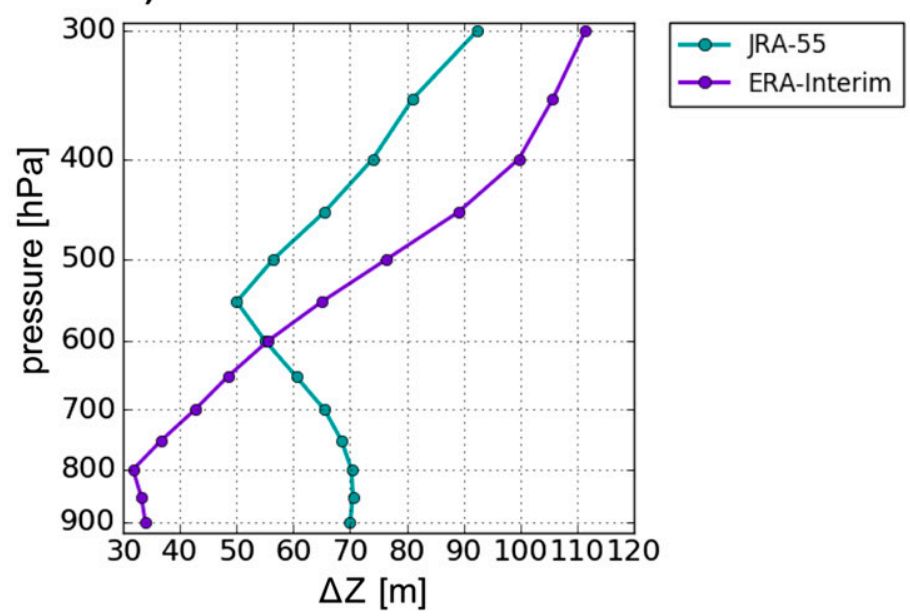
ERA-Interim

FIG. 4. Trajectory of Tropical Storm Earl (1992) in a $B$ vs $-V_{T}^{L}$ cross section of the CPS. The CPS parameters are shown (a) as calculated in JRA-55 and (b) based on ERA-Interim data, and a 24-h running mean has been used for plotting. Letters $\mathrm{A}$ and $\mathrm{Z}$ mark the beginning and end of the track, respectively. The magnitude of relative vorticity at $850 \mathrm{hPa}\left(10^{5} \mathrm{~s}^{-1}\right)$ in (c) JRA-55 and (d) ERA-Interim is shown at 0600 UTC 3 Oct 1992. (e) The $\Delta Z$ is the difference between the maximum and minimum geopotential height within a $500-\mathrm{km}$ radius about the reanalysisspecific storm center, taken at the same date and time. 


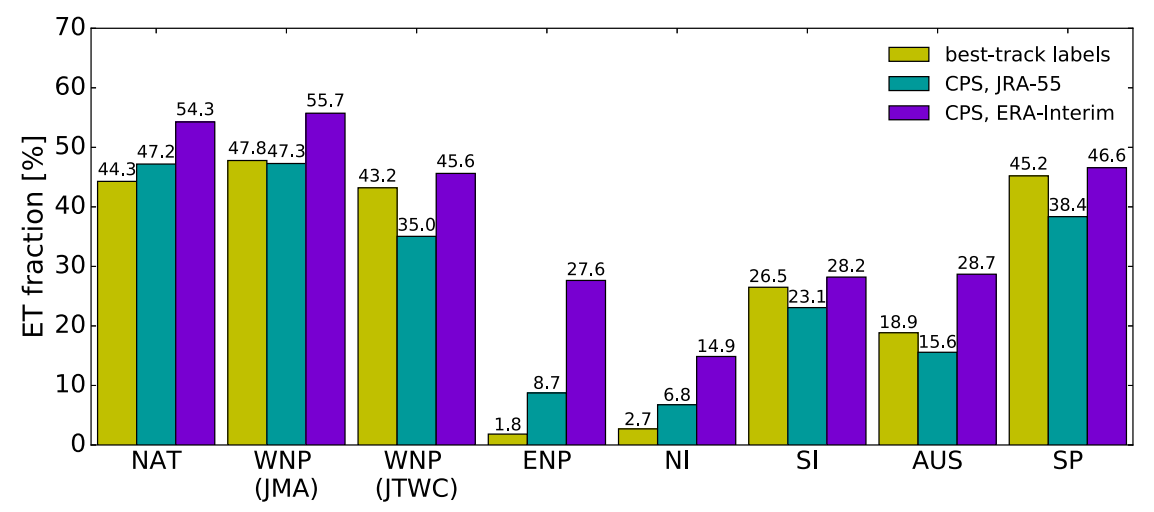

FIG. 5. Global ET fractions computed from the objective detection of ET in CPS (in JRA55 and ERA-Interim) as well as from the storm type labels assigned in the best track datasets. The time period used to calculate the ET fractions is 1979-2017 for the NAT and the WNP (JMA), 1988-2017 for the ENP, and 2004-17 for the WNP (JTWC), NI, SI, AUS, and the SP. The results for the WNP are shown for the best track archives of JMA as well as JTWC.

tracks agrees better with the observations than that obtained from the JTWC tracks (as shown in Part II), all results for the WNP presented in the rest of this study are based on the JMA archive.

The past studies on ET summarized in Table 3 provide a context for the ET fractions obtained here. Our ET percentage of $47.3 \%$ for the WNP obtained from JRA-55 is higher than the value of $40 \%$ in Kitabatake (2011), who used the JRA-25 reanalysis. Tracking North Atlantic storms in ERA-Interim, Zarzycki et al. (2016) computed an ET fraction of $55.2 \%$, which agrees with the fraction of $54.3 \%$ yielded by our ET detection in the NAT best track storms in ERA-Interim. According to Wood and Ritchie (2014), $9 \%$ of the storms in the ENP undergo ET, which is comparable to the $7.2 \%$ we obtain using the same dataset and a similar time period.

The ET fractions in Fig. 5 would be higher without the inclusion of the $-V_{T}^{U}$ parameter in the definition of ET, implying that a lower-tropospheric cold core is not necessarily preceded by the development of a cold core in the upper troposphere. The definition of ET used in this study includes the $-V_{T}^{U}$ parameter because it improves the agreement with the best tracks on a global basis, in terms of both ET fractions (Fig. S1 in the online supplemental material) and classification of individual storms (as shown in Part II).

\section{c. ET pathways in the CPS: $B \rightarrow V_{T}, V_{T} \rightarrow B$, and direct transitions}

Evans and Hart (2003) originally described ET as a transformation that starts with the TC becoming asymmetric and ends with the formation of a cold core $\left(B \rightarrow V_{T} \mathrm{ET}\right)$. Since then, a number of studies (e.g., Kitabatake 2011; Wood and Ritchie 2014; Studholme et al. 2015; Evans et al. 2017; Liu et al. 2017) have pointed out the importance of alternative pathways. In particular, Studholme et al. (2015) found that a majority of the cyclones lose their warm core before becoming asymmetric $\left(V_{T} \rightarrow B \mathrm{ET}\right)$.

Table 4 shows that the "canonical" $B \rightarrow V_{T}$ transition is the dominant ET pathway in most basins. However, there are also substantial fractions of storms that undergo a $V_{T} \rightarrow B$ transition. The canonical model of ET via the asymmetric warm core route was proposed by Evans and Hart (2003) based on the analysis of a set of 61 TCs in the NAT, all of which undergo ET according to the NHC labels (Evans and Hart 2003). Thus, it is surprising that the NAT has one of the highest fractions of $V_{T} \rightarrow B$ transitions. Considering only the subset of TCs that are diagnosed as ET storms in the CPS as well as in the NHC best tracks, the percentage of $B \rightarrow V_{T}$ ETs increases by about 6 percentage points whereas that of the $V_{T} \rightarrow B$ ETs drops by a similar amount. Hence, the canonical type of ET is indeed more common among the ETs recorded

TABLE 2. Summary of ET fractions for the time period 19792017, derived in JRA-55 and ERA-Interim. Values are given as percentages and as number of ET storms out of the total number of storms in each basin.

\begin{tabular}{lrlll}
\hline & \multicolumn{2}{c}{ JRA-55 } & \multicolumn{2}{c}{ ERA-Interim } \\
\hline NAT & $47.2 \%$ & $(227 / 481)$ & $54.3 \%$ & $(261 / 481)$ \\
WNP (JMA) & $47.3 \%$ & $(470 / 994)$ & $55.7 \%$ & $(554 / 994)$ \\
WNP (JTWC) & $32.0 \%$ & $(321 / 1002)$ & $44.9 \%$ & $(450 / 1002)$ \\
ENP & $7.2 \%$ & $(47 / 656)$ & $27.9 \%$ & $(183 / 656)$ \\
NI & $8.5 \%$ & $(16 / 188)$ & $17.6 \%$ & $(33 / 188)$ \\
SI & $12.8 \%$ & $(44 / 344)$ & $22.1 \%$ & $(76 / 344)$ \\
AUS & $16.2 \%$ & $(63 / 389)$ & $31.4 \%$ & $(122 / 389)$ \\
SP & $30.9 \%$ & $(73 / 236)$ & $44.1 \%$ & $(104 / 236)$ \\
\hline
\end{tabular}



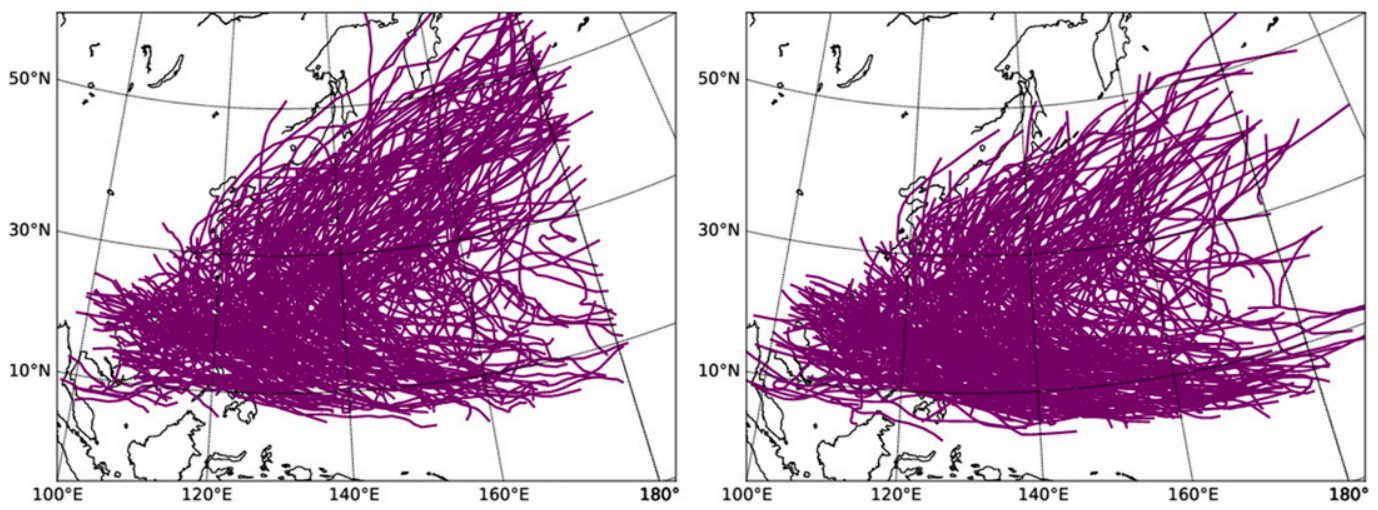

FIG. 6. TC tracks in the WNP (1990-2000), from the (left) JMA and (right) JTWC best track archives.

in the best tracks, which may partly explain its prevalence in the 61 TCs analyzed by Evans and Hart (2003).

In all basins except the ENP, ERA-Interim yields higher fractions of ETs that begin with the development of a cold core than does JRA-55. A tendency of ERAInterim toward weaker warm cores is apparent in the distribution of the $V_{T}$ parameters (Fig. 3), especially in the upper-tropospheric parameter. In a comparison of TC structure from reanalysis datasets with data from over 2000 dropsondes, Brammer and Thorncroft (2017) found that ERA-Interim has a cold bias at $300 \mathrm{hPa}$, which becomes more pronounced for more intense storms. Furthermore, Wood and Ritchie (2014) noticed a cold bias of ERA-Interim in the 900-600-hPa layer of TCs in the ENP.

The WNP has the highest relative frequency of $B \rightarrow$ $V_{T}$ transitions, while $V_{T} \rightarrow B$ ETs are most prevalent in the ENP. Wood and Ritchie (2014) noted that the cool SSTs to the west and north of the main development region in the ENP may prompt the loss of the warm core that marks the beginning of ET.

In section $3 i$, we use the results of a cluster analysis to examine different groups of ET storms and their associated trajectories in the CPS in more depth.

\section{d. Seasonal cycle}

There is considerable variability in the seasonal patterns of ET events in the different basins (Fig. 7). However, as there is a good agreement between the two reanalyses in this respect, Fig. 7 only shows the results for JRA-55. ET requires, first, the presence of a tropical region that supports the formation and intensification of TCs, and then the presence of a baroclinic region characterized by vertical wind shear and low static stability

TABLE 3. Literature overview of past studies on ET fractions in various basins (no claim to completeness). For comparison, the ET fractions obtained in this study (see Table 2) are added in parentheses (JRA-55, ERA-Interim).

\begin{tabular}{|c|c|c|c|c|}
\hline Basin & Author(s) & ET fraction & Method/data & Time period (No. of storms) \\
\hline NAT & Hart and Evans (2001) & $46 \%(47 \%, 54 \%)$ & NHC best track labels & $1950-96(463)$ \\
\hline NAT & Studholme et al. (2015) & $68 \%(47 \%, 54 \%)$ & $\begin{array}{l}\text { CPS and } k \text {-means clustering, storms tracked } \\
\text { in ECMWF operational analysis }\end{array}$ & $2000-08(72)$ \\
\hline NAT & Zarzycki et al. (2016) & $55 \%(47 \%, 54 \%)$ & CPS, storms tracked in ERA-Interim & 1980-2002 (87) \\
\hline WNP & Klein et al. (2000) & $27 \%(47 \%, 56 \%)$ & Satellite imagery, NOGAPS & 1994-98 (112) \\
\hline WNP & Kitabatake (2011) & $49 \%, 40 \%(47 \%, 56 \%)$ & JMA best track labels CPS, JRA-25 & 1974-2004 (687) \\
\hline WNP & Studholme et al. (2015) & $65 \%(47 \%, 56 \%)$ & $\begin{array}{l}\text { CPS and } k \text {-means clustering, storms tracked } \\
\text { in ECMWF operational analysis }\end{array}$ & $2000-08(111)$ \\
\hline ENP & Wood and Ritchie (2014) & $9 \%(7 \%, 28 \%)$ & CPS, JRA-55 & $1971-2012(631)$ \\
\hline ENP & Studholme et al. (2015) & $35 \%(7 \%, 28 \%)$ & $\begin{array}{l}\text { CPS and } k \text {-means clustering, storms tracked } \\
\text { in ECMWF operational analysis }\end{array}$ & $2000-08(81)$ \\
\hline NI & Studholme et al. (2015) & $31 \%(9 \%, 18 \%)$ & $\begin{array}{l}\text { CPS and } k \text {-means clustering, storms tracked } \\
\text { in ECMWF operational analysis }\end{array}$ & $2000-08(32)$ \\
\hline SI & Griffin and Bosart (2014) & $44 \%(13 \%, 22 \%)$ & $\begin{array}{l}\text { Subjective identification of ET cases in best } \\
\text { track data of Météo-France La Réunion, } \\
\text { ERA-Interim }\end{array}$ & 1989-2013 (235) \\
\hline SP & Sinclair (2002) & $32 \%(31 \%, 44 \%)$ & $\begin{array}{l}\text { Based on number of TCs reaching } \\
\text { midlatitudes }\end{array}$ & $1970-96(251)$ \\
\hline
\end{tabular}


TABLE 4. Numbers and relative frequencies of three ET pathways through the CPS: In a $B \rightarrow V_{T}$ ET, a TC first becomes asymmetric $(B>11)$ before developing a cold-core structure $\left(V_{T}^{U}<0\right.$ and $\left.V_{T}^{L}<0\right)$. In a $V_{T} \rightarrow B$ ET, the cold-core structure is established before the TC becomes asymmetric, and in direct ETs both characteristics occur at the same time step.

\begin{tabular}{lccccccc}
\hline \hline & \multicolumn{3}{c}{ JRA-55 } & & \multicolumn{3}{c}{ ERA-Interim } \\
\cline { 2 - 3 } Basin & $\begin{array}{c}B \rightarrow V_{T} \\
(\% \text { of all ETs })\end{array}$ & $\begin{array}{c}V_{T} \rightarrow B \\
(\% \text { of all ETs })\end{array}$ & $\begin{array}{c}\text { Direct } \\
(\% \text { of all ETs })\end{array}$ & & $\begin{array}{c}B \rightarrow V_{T} \\
(\% \text { of all ETs })\end{array}$ & $\begin{array}{c}V_{T} \rightarrow B \\
(\% \text { of all ETs })\end{array}$ & $\begin{array}{c}\text { Direct } \\
(\% \text { of all ETs })\end{array}$ \\
\hline NAT & $128(56.4 \%)$ & $70(30.8 \%)$ & $29(12.8 \%)$ & & $109(41.8 \%)$ & $118(45.2 \%)$ & $34(13.0 \%)$ \\
WNP & $334(71.1 \%)$ & $71(15.1 \%)$ & $65(13.8 \%)$ & & $326(58.8 \%)$ & $165(29.8 \%)$ & $63(11.4 \%)$ \\
ENP & $17(36.2 \%)$ & $22(46.8 \%)$ & $8(17.0 \%)$ & & $96(52.5 \%)$ & $74(40.4 \%)$ & $13(7.1 \%)$ \\
NI & $9(56.2 \%)$ & $3(18.8 \%)$ & $4(25.0 \%)$ & & $18(54.5 \%)$ & $11(33.3 \%)$ & $4(12.1 \%)$ \\
SI & $27(61.4 \%)$ & $7(15.9 \%)$ & $10(22.7 \%)$ & & $36(47.4 \%)$ & $33(43.4 \%)$ & $7(9.2 \%)$ \\
AUS & $39(61.9 \%)$ & $12(19.0 \%)$ & $12(19.0 \%)$ & & $76(51.0 \%)$ & $33(36.5 \%)$ & $13(12.5 \%)$ \\
SP & $43(58.9 \%)$ & $20(27.4 \%)$ & $10(13.7 \%)$ & & $53(51.0 \%)$ & $38(36.5 \%)$ & $13(12.5 \%)$ \\
\hline
\end{tabular}

that supports extratropical cyclone development (Hoskins and Valdes 1990). Figure 8 shows seasonal composites of potential intensity (Emanuel 1988), vertical wind shear, and TC steering flow, defined as a weighted average of the flow at 850 and $200 \mathrm{hPa}$ (Emanuel et al. 2006). The seasonality of the tropical and baroclinic environments encountered by TCs causes seasonal variations in the ET fraction.

In the NAT, the number of ET storms is highest in September, but the ET fraction only reaches its peak in November (Fig. 7). A similar seasonal cycle was obtained by Hart and Evans (2001) based on the storm type labels in the NHC best tracks. In summer, a TC leaving the area that supports tropical development often decays before interacting with the baroclinic zone and its associated vertical wind shear that initiates the transformation stage of ET (Klein et al. 2000). In later months, however, this gap closes because the baroclinically favorable region pushes southward and encroaches on the area over which tropical development can occur; given the large heat capacity of the ocean, this "tropically favorable" region still extends relatively far north at that time of the year (Fig. 8a), despite the retreat of the sun toward the Southern Hemisphere. Thus, the environment is most ET-friendly in October and November, which is consistent with the increased ET fraction in these months.
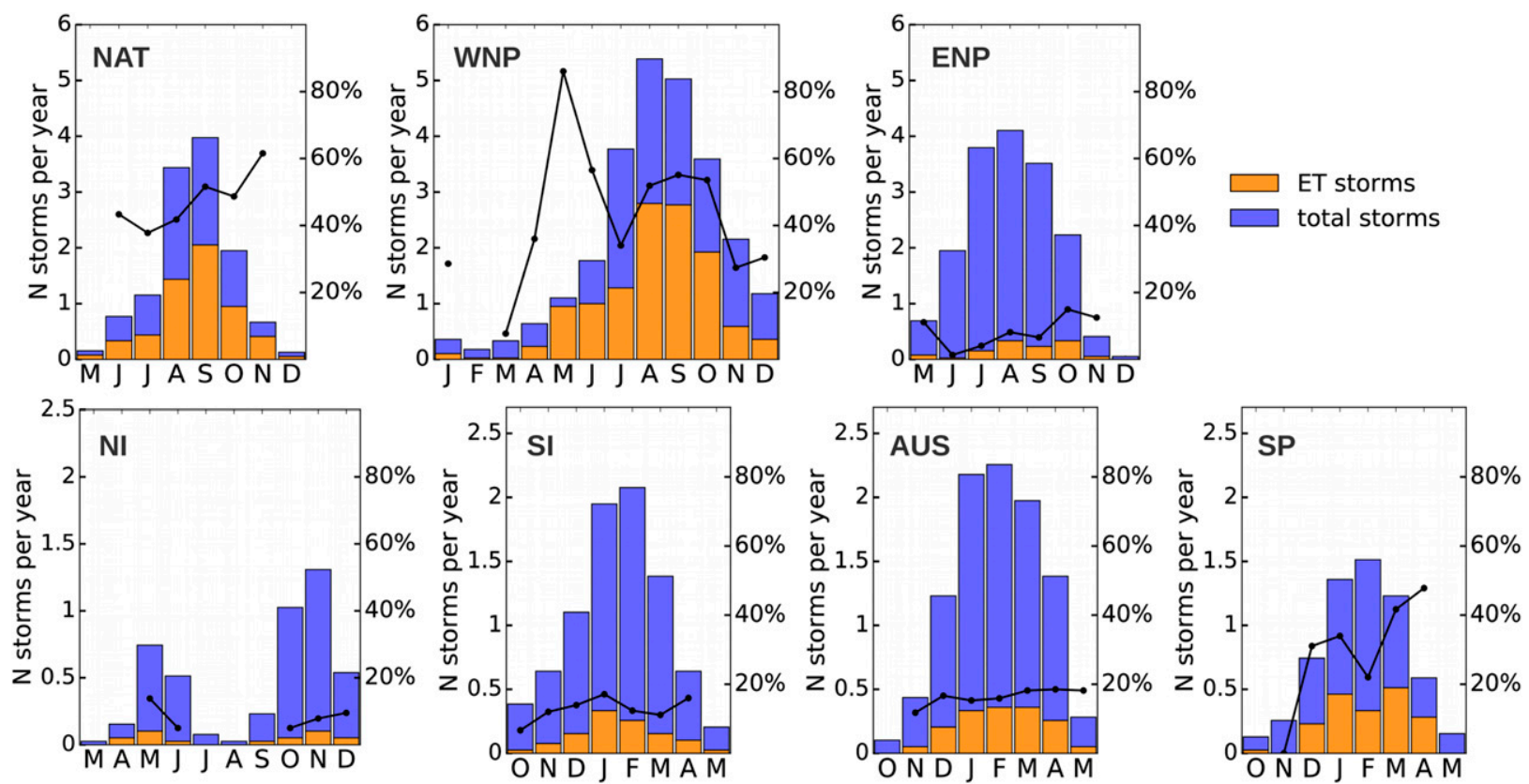

FIG. 7. Seasonal cycles of ET in terms of the average annual number of storms in each month (blue: total storms; orange: ET storms, as defined by the JRA-55 classification) for the time period 1979-2017. The black line refers to the percentage axis and shows the corresponding ET fraction, which is only calculated if a minimum of 10 storms (including non-ET storms) occurred in a given month over the whole time period. 
a) NAT
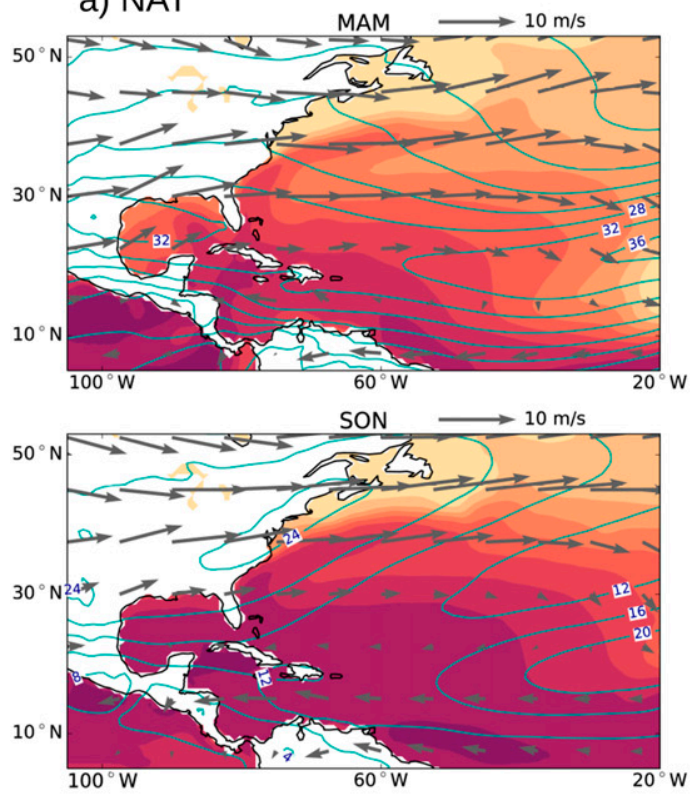
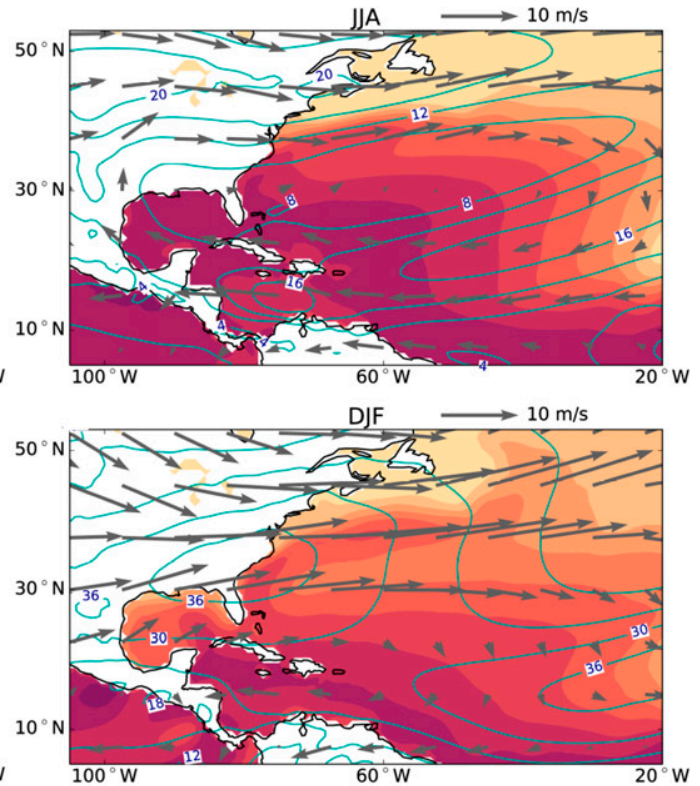

b) WNP
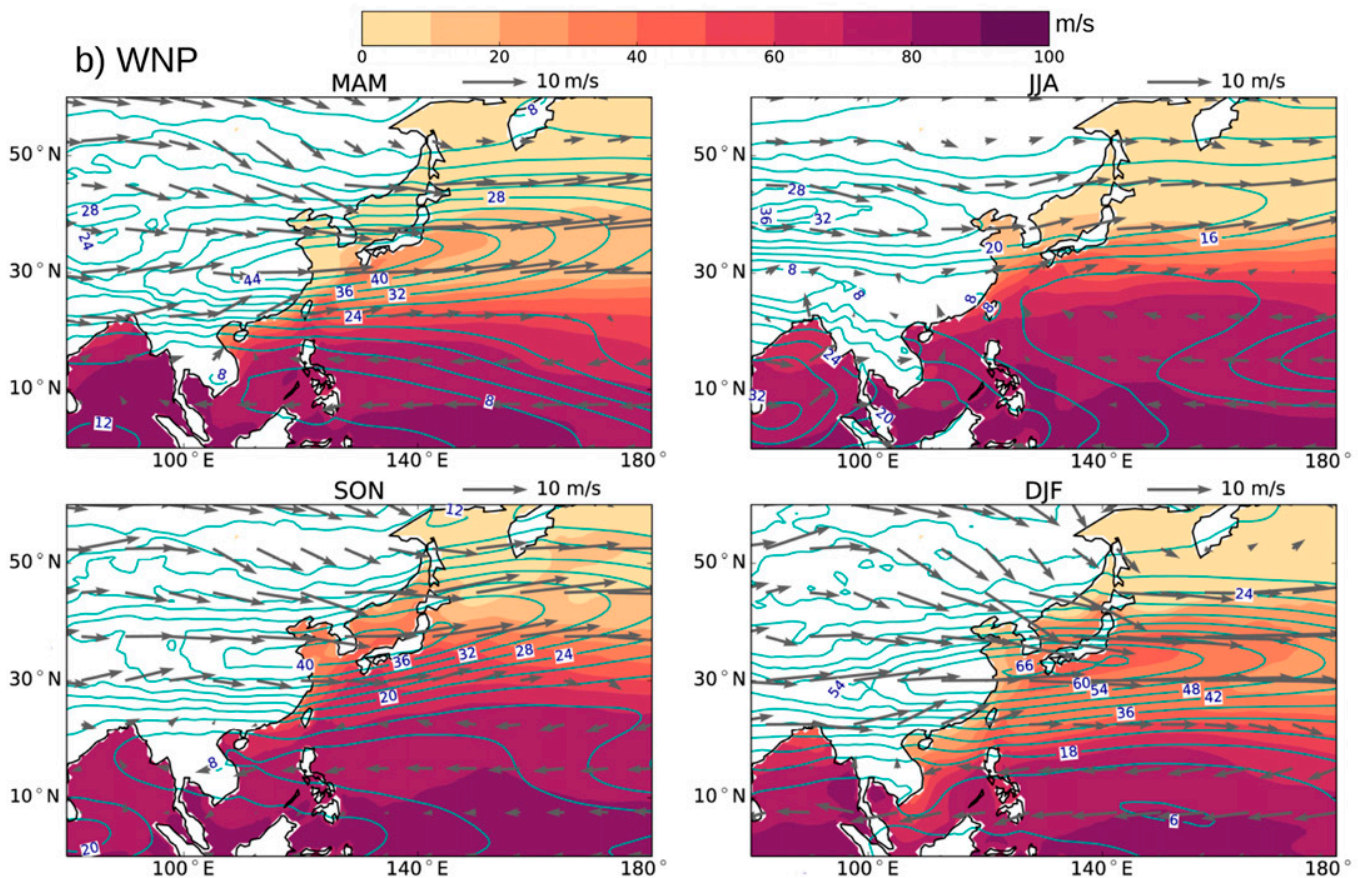

FIG. 8. Seasonal climatologies (1979-2017) in the (a) NAT and (b) WNP: potential intensity ( $\mathrm{m} \mathrm{s}^{-1}$; color shading), steering flow ( $\mathrm{m} \mathrm{s}^{-1}$; arrows), and vertical wind shear $\left(\mathrm{m} \mathrm{s}^{-1}\right.$; blue contour lines). The steering flow $\mathbf{V}$ is a weighted average of the large-scale low-level $(850 \mathrm{hPa})$ and upper-level $(200 \mathrm{hPa})$ winds: $\mathbf{V}=0.8 \mathbf{V}_{850 \mathrm{hPa}}+$ $0.2 \mathbf{V}_{850 \mathrm{hPa}}$. The vertical wind shear is the magnitude of the vector difference between the wind at $200 \mathrm{and} 850 \mathrm{hPa}$. All fields are from ERA-Interim. MAM: March-May, JJA: June-August, SON: September-November, DJF: December-February.

The WNP shows a double peak in May and September, which is consistent with the result of Kitabatake (2011). In contrast to the other basins, the WNP has TCs forming all year round. In May, the frequency of recurving storms (which are most likely to undergo ET) is not much above the annual average, but the ET fraction of those storms that do recurve is about 95\% (not shown). With the northward migration of the jet stream in summer (e.g., Schiemann et al. 2009), the TCs become less likely to interact with midlatitude westerlies and 
high vertical wind shear (Fig. 8b). In September, the jet starts to intensify and intrude southward (Schiemann et al.2009), and the monsoon trough, a preferred genesis region for TCs, reaches its northernmost extension (Molinari and Vollaro 2013). In this setting, TCs can form at relatively high latitudes $\left(15^{\circ}-20^{\circ} \mathrm{N}\right)$ and are likely to get caught by the midlatitude flow, resulting in a second peak of the ET fraction. While the transition probability in the WNP decreases after September, it continues to rise in the NAT until the end of the season. The decrease of the ET fraction in the WNP in late fall coincides with the development of a zone of high vertical wind shear (Fig. 8b), which restricts the formation of TCs to the Pacific warm pool and low latitudes (Camargo et al. 2007c). TCs originating in these regions often move in straight westward tracks, whereas recurving storms tend to form farther north (Camargo et al. 2007c) and are thus less common during that time of the year.

With the exception of the SP, the SH basins exhibit less pronounced seasonal cycles of ET than the NAT or the WNP. In the SH, the extension of the subtropical jet into tropical latitudes constrains the tracks of TCs to lower latitudes than in the Northern Hemisphere (Krishnamurti et al. 2013). In addition, the seasonal change of the baroclinic energy source is relatively small except near the Antarctic (Zhu 2003). Thus, throughout the year, TCs in the SH encounter a fairly strong baroclinic environment already at low latitudes, which is illustrated in Fig. 9. Compared to the other basins, the NI and the ENP have low ET rates and do not show a clear seasonality.

\section{e. Spatial patterns}

Defining the track density as the sum of all best track data points located in each $1.25^{\circ} \times 1.25^{\circ}$ box of the latitude/longitude grid used in JRA-55, Fig. 10 compares the spatial distributions of ET storms with those of nonET storms, using the JRA-55 classification. Track densities from ERA-Interim (not shown) qualitatively agree with those from JRA-55. To first order, TCs are steered by the predominant large-scale circulation: After their formation in the tropics, they generally track westward in the easterly flow on the equatorward side of a subtropical ridge. Then, moving around the periphery of the anticyclone, they drift poleward until they possibly recurve with the midlatitude westerlies. This general track pattern holds in all basins except in the SP, where a majority of the storms move in a southwestward direction (e.g., Ramsay et al. 2012).

Because of the scarcity of ET events in the NI and the ENP, this part of the analysis focuses on the NAT, the WNP, and the SH. In the NAT and the WNP, ET storms
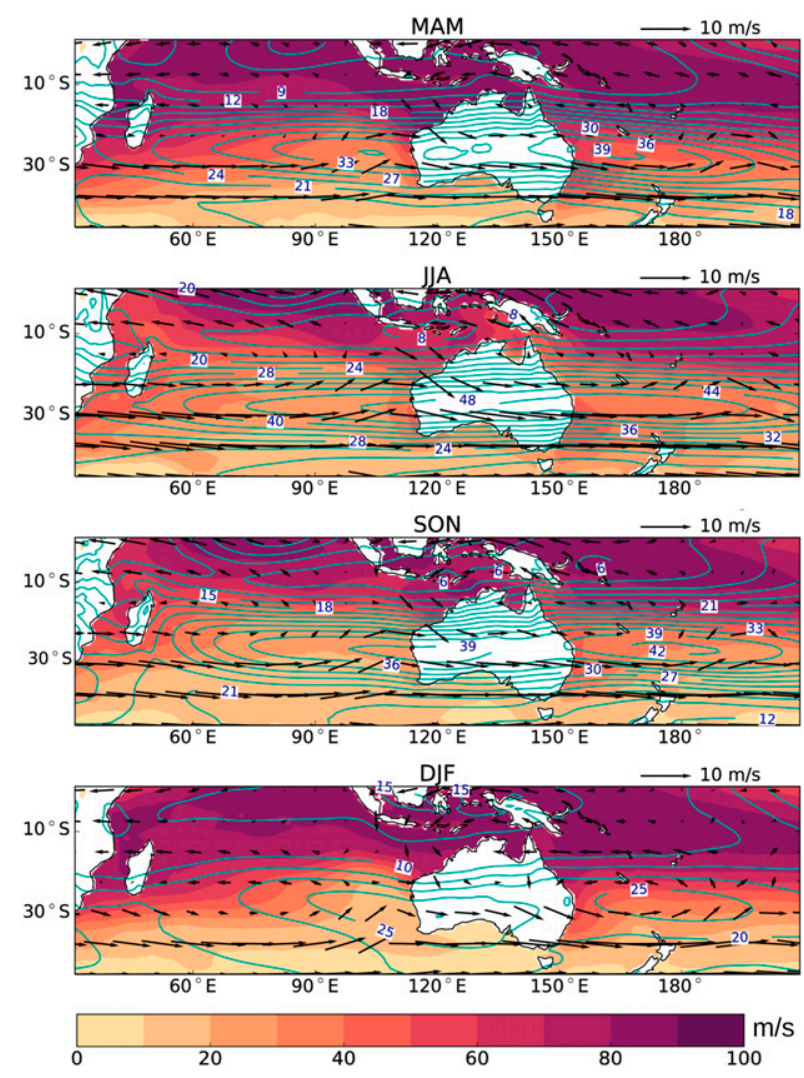

FIG. 9. Seasonal climatologies (1979-2017) in the SH basins: potential intensity $\left(\mathrm{m} \mathrm{s}^{-1}\right.$; color shading), steering flow $\left(\mathrm{m} \mathrm{s}^{-1}\right.$; arrows), and vertical wind shear ( $\mathrm{m} \mathrm{s}^{-1}$; blue contour lines). The steering flow $\mathbf{V}$ is a weighted average of the large-scale low-level $(850 \mathrm{hPa})$ and upper-level $(200 \mathrm{hPa})$ winds: $\mathbf{V}=0.8 \mathbf{V}_{850 \mathrm{hPa}}+$ $0.2 \mathbf{V}_{850 \mathrm{hPa}}$. The vertical wind shear is the magnitude of the vector difference between the wind at 200 and $850 \mathrm{hPa}$. All fields are from ERA-Interim. MAM: March-May, JJA: June-August, SON: September-November, DJF: December-February.

recurve to a greater extent than the non-ET storms, which typically follow an east-west path with less poleward drift. As a result of this recurvature, the highest density of ET storms in the WNP is found in the East China Sea, while the concentration of non-ET storms peaks farther southwest, in the South China and Philippine Seas. The track density in the NAT is more homogeneously distributed throughout the basin than in the WNP, but the general pattern is similar: ET storms most frequently pass the area off the coast of the southeast United States, and non-ET storms have their highest density southwest of that area, in the Gulf of Mexico (Fig. 10).

Most SH storms that undergo ET occur northeast of Australia, mainly in the SP. The density of non-ET storms in this region is rather low compared to the SI and the western part of the AUS. Thus, the storms passing that area have a high probability of transition. 

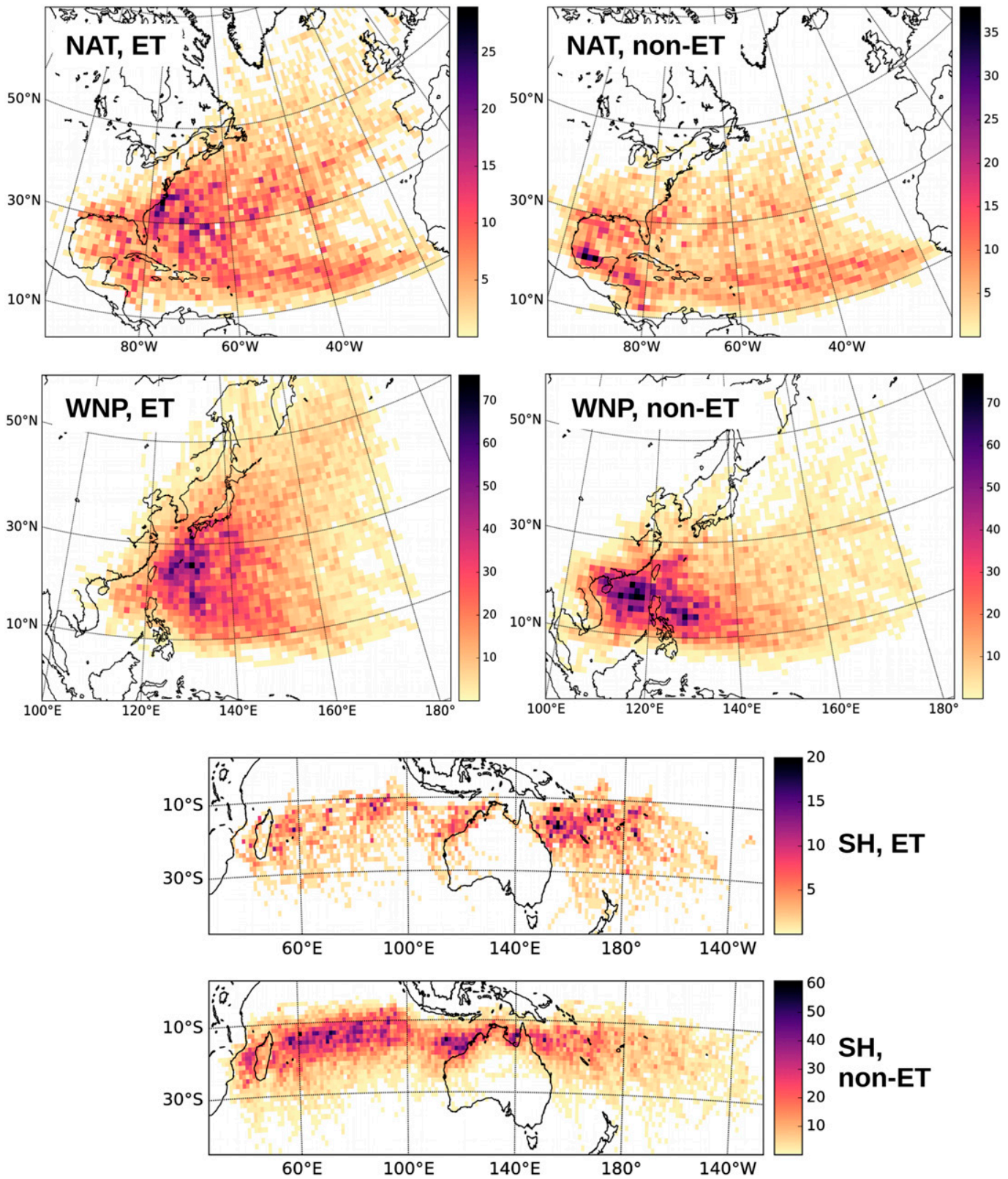

FIG. 10. Track density of ET storms and non-ET storms (as defined by the JRA-55 classification) in the NAT, the WNP, and the $\mathrm{SH}$, showing the sum of all best track data points falling into each $1.25^{\circ} \times 1.25^{\circ}$ grid box over the time period 1979-2017.

Indeed, the ET fraction in the SP reaches $50 \%$ at its peak in April, while the ET fractions of the SI and the AUS remain below $20 \%$ throughout the year (Fig. 7).

The genesis locations of ET storms and non-ET storms (not shown) are fairly similar. There is no localized "hot spot" of ET storm formation in any Northern Hemisphere basin-in fact, the genesis positions of ET storms in the NAT and the WNP are overall more homogeneously distributed than those of their non-ET counterparts. However, this relatively even spread of genesis locations in the cumulative view does not preclude the existence of seasonal variations [e.g., such as those found in the NAT by Hart and Evans (2001)]. In the SH, ET storms predominantly form in the SP, which is the region where we also find the highest track density of ET storms.

Statistics of the latitudes where TCs complete their transitions into extratropical cyclones are given in 
Fig. 11. The median latitude of ET completion in the seven basins ranges from about $20^{\circ}$ to $40^{\circ}$, and these interbasin variations are greater than the differences between the two reanalyses. In the NAT and the WNP, ET completion takes place farther poleward than in the other basins, especially in the peak season, over the warm ocean currents along the western boundaries of these basins (not shown). Both basins exhibit an annual cycle of ET latitude: Transition occurs at higher latitudes during the peak of the season and shifts to lower latitudes during the early and later months. In the NAT, these seasonal patterns of ET latitude are negatively correlated with those of the ET fractions (Fig. 7); that is, months with high ET fractions (e.g., November) have lower latitudes of ET completion, and vice versa. The correlation is not as strong in the WNP, where the decreasing ET latitudes in October-December are not associated with an increase in ET fraction. This is consistent with the idea that straight-moving storms are prevalent in the WNP at that time of the year.

The SH ETs occur at lower latitudes than in the NAT and the WNP and do not have a distinct seasonal pattern. These features are consistent with the narrower latitudinal extent of the TC tracks in the $\mathrm{SH}$, which reduces the exposure to the seasonal effects of advancing and retreating regions of baroclinic activity. The median latitudes of ET completion in the ENP and the NI are similar to those of the SH basins, but due to the scarcity of ET in these basins Fig. 11 does not show their monthly statistics.

\section{f. Interannual variability and relationship with ENSO, AMM, and PMM}

Time series of annual ET fractions (Fig. 12) reveal the interannual variability in the percentages of storms undergoing ET. The magnitudes of the year-to-year fluctuations in each basin reflect the variances in the distributions of the annual ET counts, which are driven both by variances in the number of TCs that transition and the annual TC counts. For example, the high variability in the NI results from the combination of a small number of ET storms and a low overall storm count. Except for the JRA-55 time series in the ENP and the SI, the slopes of the linear regression lines are not statistically significant at the 0.95 confidence level (Table 5). Figure 12 also shows that the higher overall ET fractions associated with the CPS parameters calculated in ERAInterim (Fig. 5 and Table 2) are present in nearly all individual years.

Analyses in each basin of the best track time series of ET fractions using a Poisson model of constant annualmean TC formation and a constant probability per TC of undergoing ET suggest that the interannual variability is largely consistent with a stationary random process in the NAT, WNP, AUS, and the SI (not shown). Also, there is no significant lag-1 autocorrelation in any of these time series (not shown), indicating the absence of year-to-year memory in the transition probability. Because of low ET and/or total TC counts, autocorrelation and consistency with a Poisson process were not evaluated for the ENP, NI, or SP.

The correlations between the time series of JRA-55 and ERA-Interim (Table 5) are high and statistically significant for the NAT and the WNP. In the SI, the SP, and the NI, the correlations between the ET fractions in the two reanalyses are also statistically significant, but weaker.

Natural climate variability strongly modulates the seasonal statistics of TCs. In most basins, ENSO is the primary driver of variability (Frank and Young 2007). ENSO exerts a well-defined control on TC occurrence and tracks in the WNP and the NAT (e.g., Wang and Chan 2002; Camargo and Sobel 2005; Bell and Chelliah 2006). Atlantic TC activity is also influenced by the Atlantic meridional mode, which is associated with shifts in the cyclone genesis regions on interannual-todecadal time scales (Vimont and Kossin 2007). Similarly, the Pacific meridional mode has been associated with changes in TC activity in the WNP, with the positive PMM phase favoring the genesis of TCs and the negative PMM phase inhibiting their occurrence (Zhang et al. 2016).

Using the JRA-55 classification, only the AUS region's annual ET fraction is significantly correlated with the Niño-3.4 index in the basin average (Table 6). Its lower ET fraction during El Niño years may be explained by a reduced genesis potential in the Coral Sea (Camargo et al. 2007a), where most ET storms in the AUS form (Fig. 10).

The known connections between the AMM and TC activity in the NAT (e.g., Vimont and Kossin 2007; Kossin et al. 2010), the WNP (Zhang et al. 2017), and the ENP (Patricola et al. 2017) do not manifest themselves in significant correlations with the ET fractions. In the statistics from the ERA-Interim classification (not shown), the enhancement of the ET fraction during El Niño years in the WNP is the only significant relationship.

The absence of robust correlations suggests that ENSO, AMM, and PMM exert their influence in ways whose net effect leaves the annual ET fraction unchanged (e.g., by changing the number of TCs rather than their tracks). Furthermore, there are no significant differences in the monthly ET fractions between El Niño and La Niña years, as the changes in the monthly ET storm counts tend to be proportional to the changes in the total storm counts (Fig. S2). 

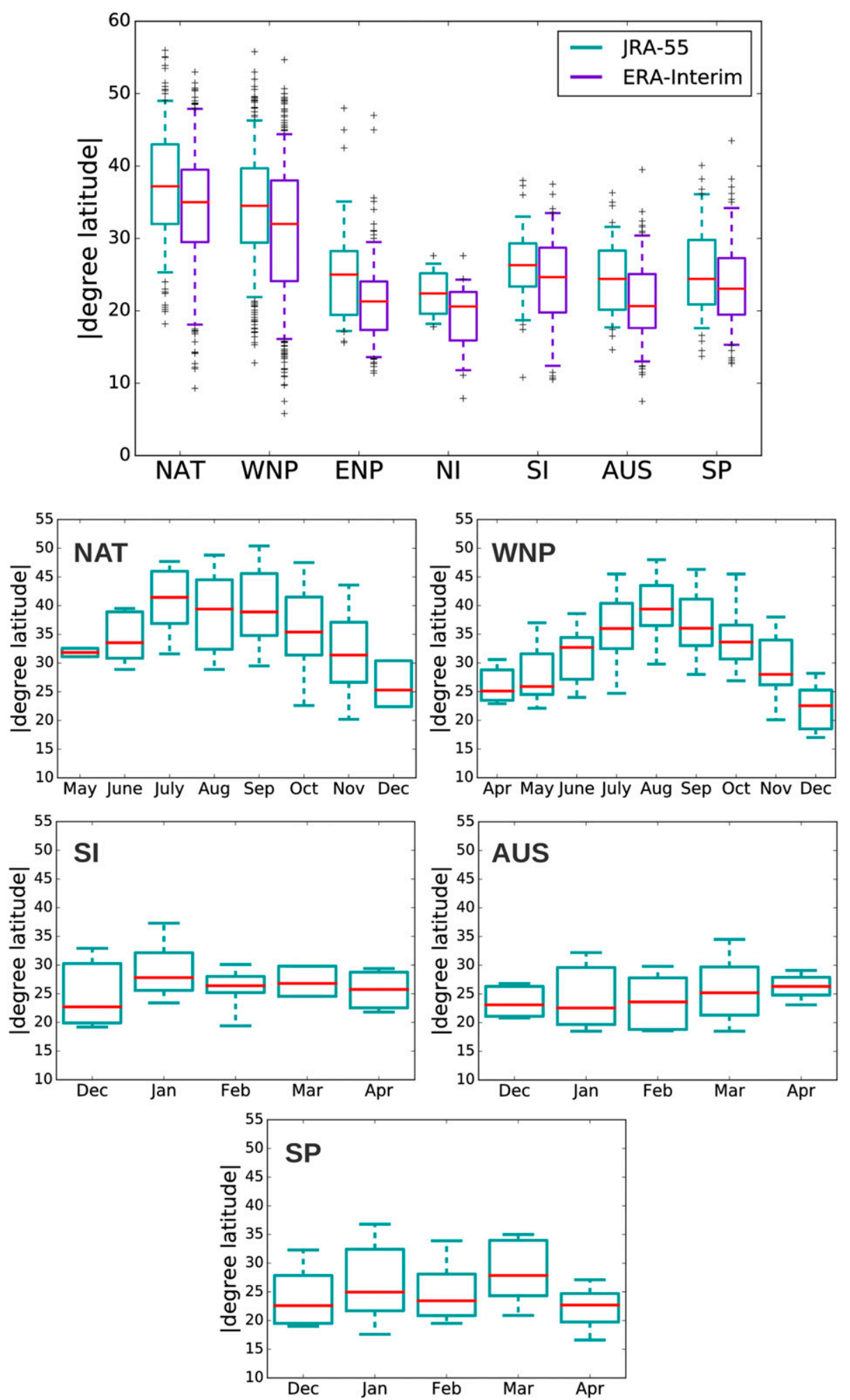

FIG. 11. (top) Boxplots of the absolute values of the latitudes at which storms complete ET, for all basins and all ETs in 1979-2017 (for JRA-55 and ERA-Interim) and (bottom) decomposition into seasonal cycles for the NAT, WNP, SI, AUS, and the SP (for JRA-55). The box extends from the lower to the upper quartile, with a red line at the median, and the whiskers extend from the 5 th to the 95th percentile. The monthly statistics for the ENP and the NI have been excluded due to the scarcity of ET events in those basins. 

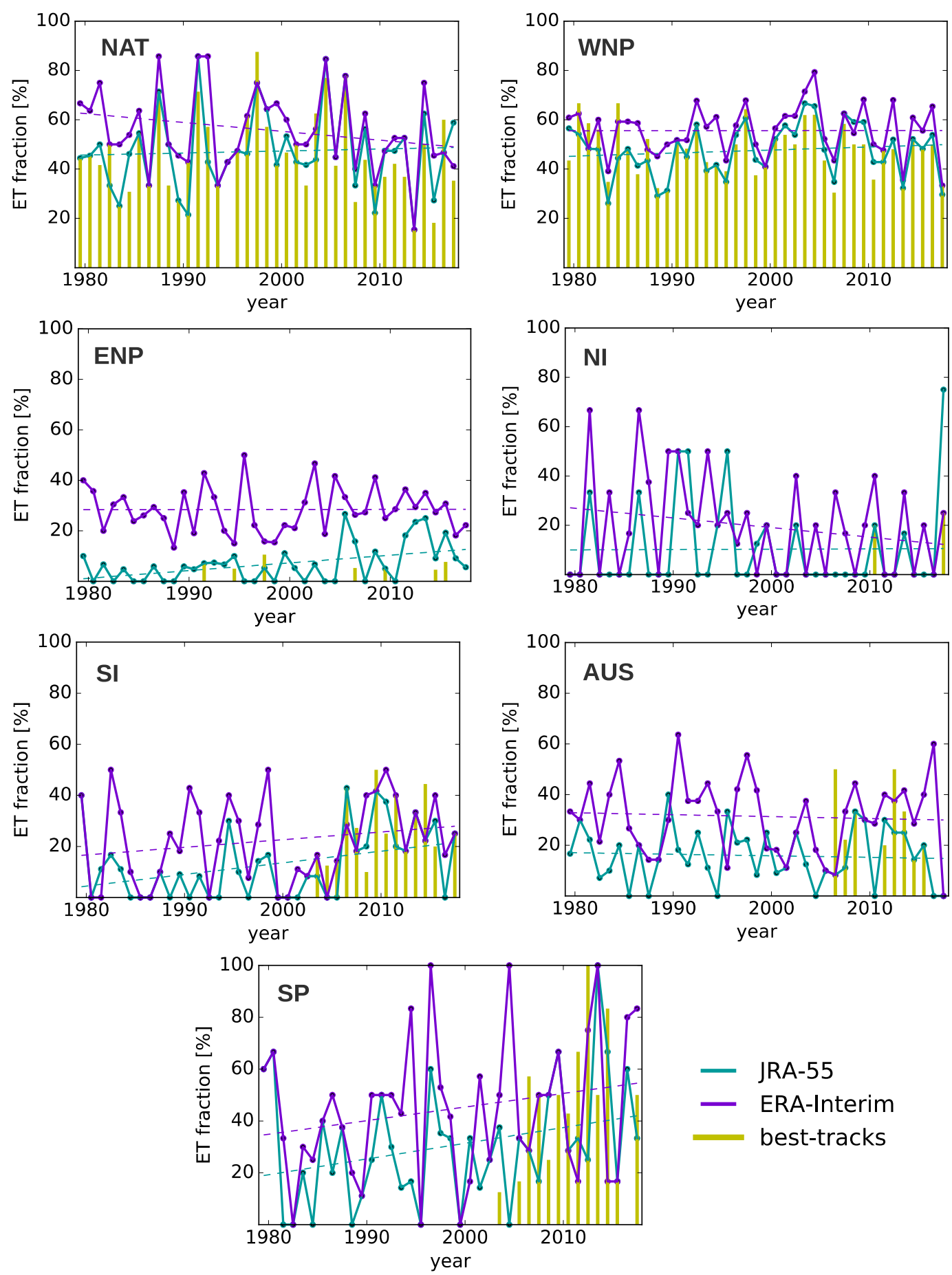

FIG. 12. Time series of annual ET fractions from 1979 to 2017, for JRA-55 and ERA-Interim, with dashed lines representing the linear regression best fits to the time series. The vertical bars show the ET fractions derived from the best track labels.

While an ENSO signal is all but absent in the basinwide ET fraction, it is present in the spatial distribution of ET events within the basin. For the NAT and the WNP, Fig. 13 shows the difference between the track density of ET storms occurring during the peak season of El Niño years and those forming during the peak season of La Niña years, normalized by the number of El Niño and La Niña years, respectively. In the WNP, 
TABLE 5. Statistics of the time series of ET fractions: sample mean and standard deviation (JRA-55, ERA-Interim), $p$ value of the slope of the linear regression lines (JRA-55, ERA-Interim), Pearson correlation coefficient $R$ between the JRA-55 and the ERA-Interim time series, and $p$ value of that correlation coefficient. Statistically significant values are in bold.

\begin{tabular}{lcccrr}
\hline \hline Basin & Mean $(\%)$ & Std dev $(\%)$ & $p$ value of slope & $R$ & $p$ value of $R$ \\
\hline NAT & $47.2,55.9$ & $16.5,16.3$ & $0.736,0.127$ & 0.78 & $<.84$ \\
WNP & $47.5,55.6$ & $10.3,10.0$ & $0.412,0.985$ & 0.17 & $<\mathbf{0 . 0 0 1}$ \\
ENP & $6.8,28.4$ & $7.4,9.0$ & $\mathbf{0 . 0 0 3}, 0.973$ & 0.46 & 0.289 \\
NI & $10.3,19.7$ & $18.4,19.5$ & $0.959,0.168$ & 0.67 & $\mathbf{0 . 0 0 4}$ \\
SI & $12.9,22.2$ & $13.5,16.2$ & $\mathbf{0 . 0 1 7}, 0.202$ & 0.22 & 0.0 .001 \\
AUS & $15.9,31.4$ & $10.8,14.6$ & $0.700,0.725$ & 0.50 & $\mathbf{0 . 0 0 1}$ \\
SP & $30.5,44.6$ & $23.0,27.1$ & $0.067,0.183$ & & \\
\hline
\end{tabular}

cyclones in El Niño years have a stronger tendency to recurve northeastward and reach latitudes farther north (Wang and Chan 2002). The mean cyclone genesis region is displaced to the southeast during El Niño years (Chia and Ropelewski 2002; Wang and Chan 2002). These two associations are consistent with Fig. 13: During El Niño years, more storms form in the easternmost genesis region, and more storms recurve toward high latitudes. Moving to the east of China, they enter a region with anomalously high wind shear (Kim et al. 2011), inhibiting their tropical development and favoring ET. This translates into a positive (though not significant) correlation between the annual fraction of storms undergoing ET and the Niño-3.4 index (Table 6). There are no ENSO-related changes in the latitude of ET onset and ET completion (Fig. S3) that are significant and consistent for both reanalyses.

In the NAT, TC activity is generally reduced during El Niño years (e.g., Gray 1984), and the same is the case when considering only ET storms (Fig. 13). However, Fig. 13 also shows an increased track density in parts of the Caribbean and the U.S. East Coast, which is typical of central Pacific El Niño events (Kim et al. 2009).

\section{g. Landfall}

TC damage largely depends on storms that make landfall, and some of these storms undergo ET before, while, or after they hit the coast. ET changes the structure and the nature of the hazards to coastal populations and infrastructure compared to pure TCs (e.g., Jones et al. 2003; Loridan et al. 2014; Evans et al. 2017), which makes it useful to understand the frequency and geographic distribution of such landfalls. Table 7 provides a summary of the landfall events recorded in the best track data, dividing the storms into tropical storms, transitioning storms, and extratropical storms (i.e., storms that have completed ET). Note that this classification refers to the nature of a storm at the time when the landfall occurs and does not make any statement on its further structural evolution; for example, a TC that does not show any signs of a transition when reaching land might still undergo ET at a later stage despite falling into the "tropical" category in Table 7. Landfall, defined here as the crossing of the storm center over land after being over water, is determined using a high-resolution land/ sea mask (Wessel and Smith 1996). If a single TC makes multiple landfalls, we count each individual landfall.

As a result of the geometries of the basins and the predominant large-scale circulations, the landfall ratios span a large range: At the extreme ends, three out of four storms in the NI move over land at least once in their lifetimes, but only about one out of seven in the ENP. In all basins, storms with tropical characteristics account for the majority of all landfall events, and more landfalling storms are of tropical nature in JRA-55 than in ERA-Interim. The NAT and the WNP, which have

TABLE 6. Linear correlations between time series of the Niño-3.4, AMM, and PMM indices and the annual ET fraction (based on the JRA55 classification): Pearson correlation coefficients $R$ and their $p$ values. Statistically significant values are in bold.

\begin{tabular}{|c|c|c|c|c|c|c|}
\hline & \multicolumn{2}{|c|}{ Niño-3.4 } & \multicolumn{2}{|c|}{ AMM } & \multicolumn{2}{|c|}{ PMM } \\
\hline & $R$ & $p$ value & $R$ & $p$ value & $R$ & $p$ value \\
\hline NAT & 0.14 & 0.401 & 0.09 & 0.569 & -0.18 & 0.286 \\
\hline WNP & 0.30 & 0.062 & 0.02 & 0.905 & 0.03 & 0.879 \\
\hline ENP & 0.15 & 0.347 & 0.20 & 0.224 & -0.22 & 0.186 \\
\hline NI & -0.02 & 0.883 & 0.07 & 0.692 & 0.28 & 0.084 \\
\hline SI & -0.08 & 0.633 & 0.16 & 0.340 & -0.02 & 0.910 \\
\hline AUS & -0.43 & 0.006 & 0.12 & 0.472 & -0.05 & 0.774 \\
\hline SP & -0.02 & 0.928 & 0.23 & 0.168 & 0.03 & 0.866 \\
\hline
\end{tabular}




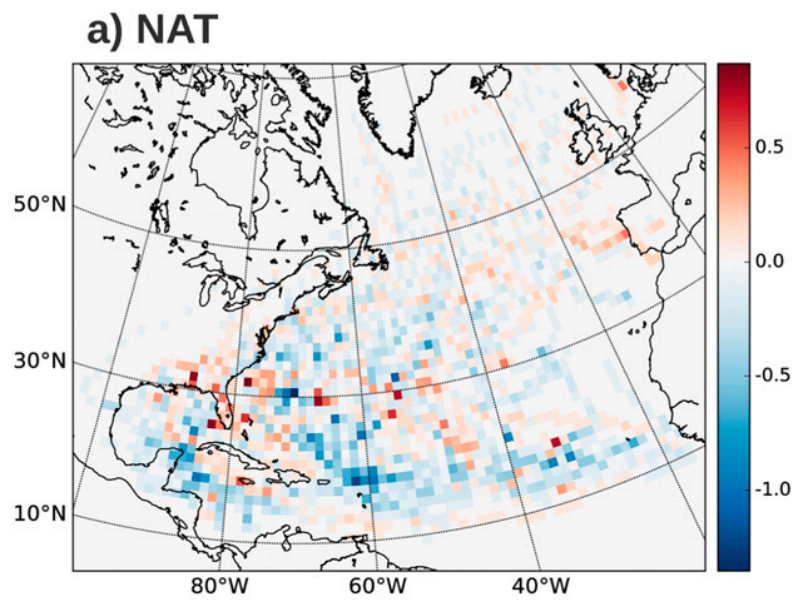

b) WNP

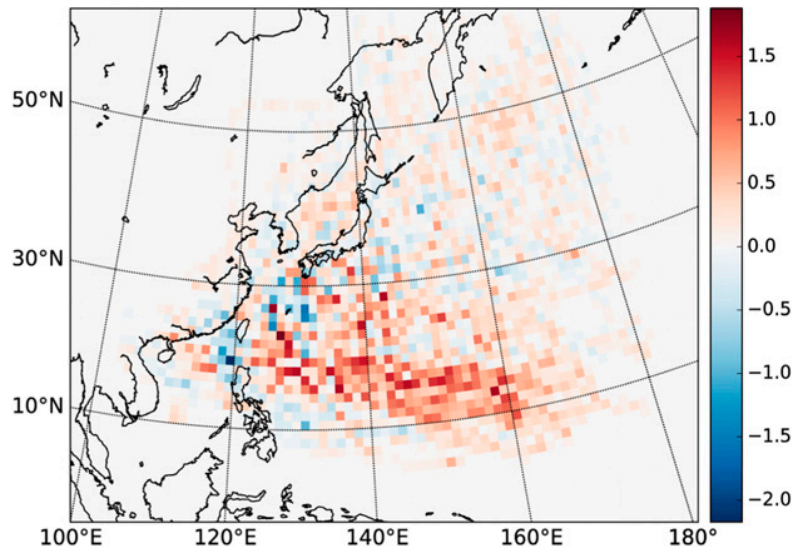

FIG. 13. Difference in the spatial distribution of ET storms (as defined by the JRA-55 classification) between El Niño and La Niña years in (a) the NAT and (b) the WNP. The colors represent the difference between the sum of all best track data points of ET storms falling into each $1.25^{\circ} \times 1.25^{\circ}$ grid box during El Niño years and the corresponding sum of track points during La Niña years. The two sums are normalized by the number of El Niño and La Niña years, respectively.

the highest overall ET fractions, also have the highest fractions of landfalls by transitioning or extratropical systems.

There is a discrepancy between JRA-55 and ERAInterim in the ENP: According to the JRA-55-based CPS parameters, almost $90 \%$ of all landfalling storms are symmetric and warm cored, while ERA-Interim classifies a fourth of them as extratropical. This suggests that ERA-Interim's higher overall ET fraction (Fig. 5) is the result of TCs that undergo ET over the ocean, rather than a consequence of structural changes in the wake of landfalls that might push storms into the asymmetric region of the CPS or increase the average position difference between the storm center in the best tracks and that in the reanalysis. It is notable that in

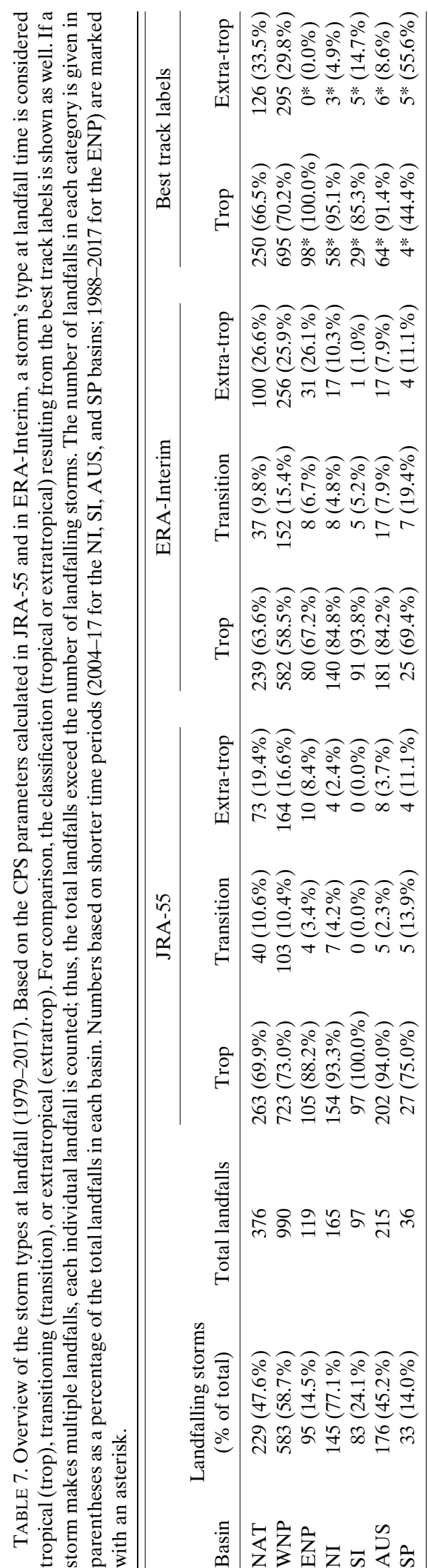



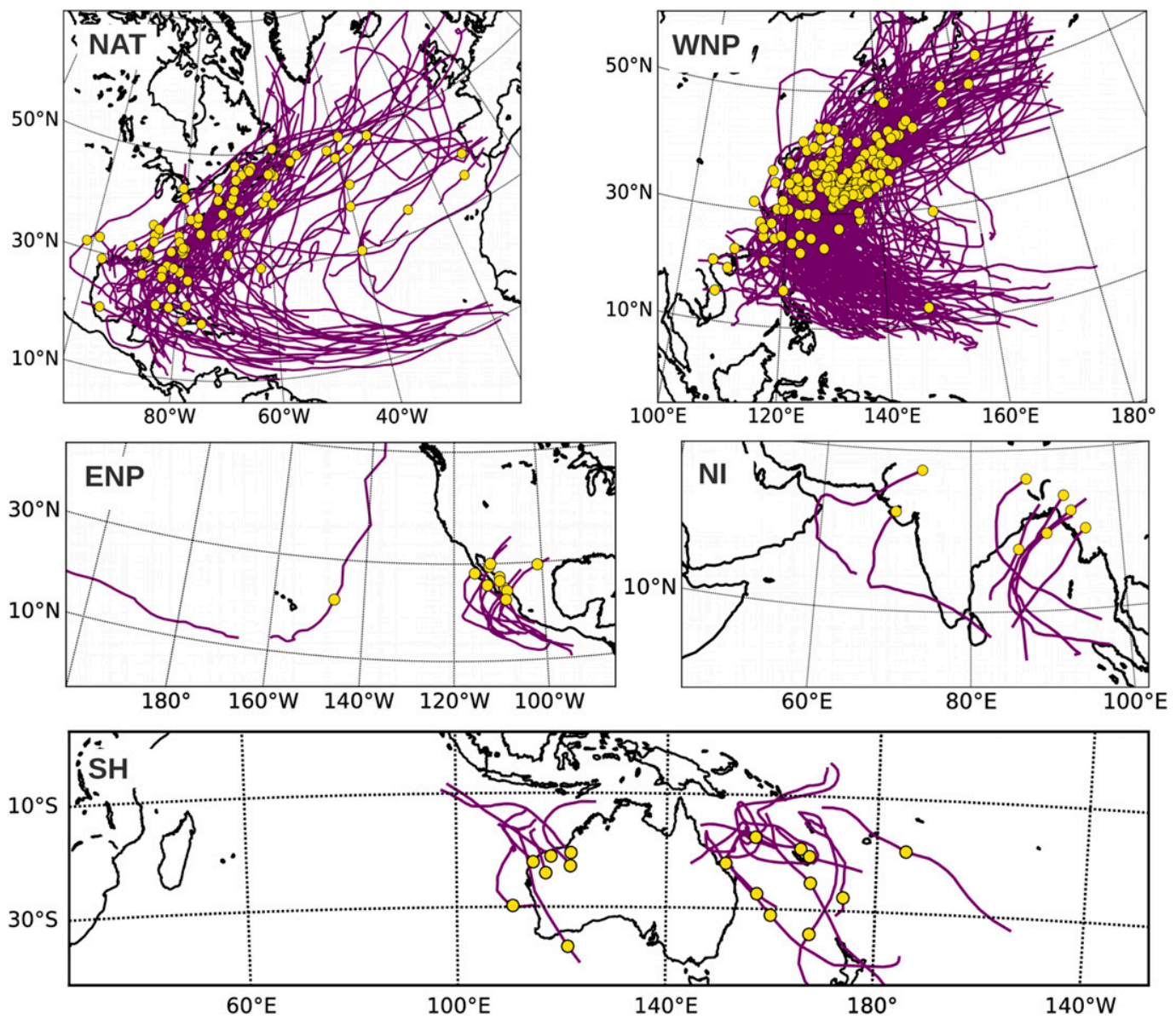

FIG. 14. Tracks of storms that make landfall as transitioning or extratropical systems (according to the JRA-55 classification), for the time period 1979-2017. The yellow dots mark the locations of ET completion.

terms of absolute numbers, the difference in the WNP267 landfalls by transitioning or extratropical storms in JRA-55, compared to 408 in ERA-Interim-is even higher than that in the ENP. The more tropical characteristics of JRA-55 TCs may be related to the artificial wind profile retrievals used in the data assimilation process (Ebita et al. 2011).

Figure 14 shows the tracks of all TCs that make landfall as a transitioning or extratropical system at least once in their lifetimes. The locations of ET completion in the WNP are clustered in a region between about $25^{\circ}$ and $45^{\circ} \mathrm{N}$ centered over Japan, whereas completion in the NAT happens preferentially along the east coast of the United States and Canada. In both basins, the tracks in Fig. 14 represent about $85 \%$ of the total landfalling storms that undergo ET at some point in their lives; that is, approximately $15 \%$ of the landfalling storms that undergo ET only begin to transition after the (last) landfall. When staying over land, such "post-landfall transitioners" can still cause substantial damage during and after their transition (e.g., Sousounis and Desflots 2010).

Given that the WNP and the NAT have the most ET storms overall, it is not surprising that coastal regions in these basins are most frequently affected by transitioning or extratropical storms. During the 1979-2017 period, such landfall events happen about 3-4 times per year in the NAT and 7-10 times per year in the WNP. In the SH, landfalling ET storms mainly pose a threat within the AUS region, especially Western Australia and the islands in the Coral and Tasman Seas. However, with a frequency of about one ET landfall every 1-2 years, the rate is lower than in the NAT or the WNP.

\section{h. Transition time periods}

Defining the transition period as the time between the onset and the completion of ET, we find that in most basins, the average ET takes 1-2.5 days. Table 8 lists all transition periods together with the $p$ value of a twosided $t$ test on the sample means of the two reanalyses in 
TABLE 8. Statistics of transition time periods: number of ET events (1979-2017), sample mean, and standard deviation of the transition periods in each basin, for the JRA-55 and the ERA-Interim ET classifications. Also shown is the $p$ value of a two-sided $t$ test on the sample means of JRA-55 and ERA-Interim, with statistically significant values in bold.

\begin{tabular}{|c|c|c|c|c|c|c|c|c|c|}
\hline & \multicolumn{4}{|c|}{ JRA-55 } & \multicolumn{4}{|c|}{ ERA-Interim } & \multirow[b]{2}{*}{$p$ value } \\
\hline & No. of ET events & Mean (h) & Median (h) & Std dev (h) & No. of ET events & Mean (h) & Median (h) & Std dev (h) & \\
\hline NAT & 227 & 46 & 24 & 68 & 261 & 50 & 24 & 63 & 0.585 \\
\hline WNP & 470 & 35 & 18 & 47 & 554 & 59 & 30 & 67 & $<\mathbf{0 . 0 0 1}$ \\
\hline ENP & 47 & 30 & 18 & 43 & 183 & 64 & 42 & 64 & $<\mathbf{0 . 0 0 1}$ \\
\hline NI & 16 & 28 & 6 & 44 & 33 & 42 & 24 & 33 & 0.744 \\
\hline SI & 44 & 32 & 12 & 48 & 76 & 52 & 30 & 56 & 0.256 \\
\hline AUS & 63 & 32 & 6 & 53 & 122 & 63 & 27 & 82 & 0.029 \\
\hline SP & 73 & 40 & 18 & 63 & 104 & 41 & 19 & 58 & 0.131 \\
\hline
\end{tabular}

each basin. However, comparing the transition periods between individual basins is not possible due to the large interreanalysis differences; for example, in the WNP, the CPS parameters from ERA-Interim yield a mean transition period of $59 \mathrm{~h}$, which is one day longer than the average ET duration in JRA-55. The transition periods of ERA-Interim are longer than those of JRA-55 in all other basins as well.

Evans and Hart (2003) obtained a mean transition period of about $33 \mathrm{~h}$ for the NAT, which is less than the $50 \mathrm{~h}(46 \mathrm{~h})$ from ERA-Interim (JRA-55). Our results for the WNP also exceed the average ET duration of about $17 \mathrm{~h}$ found by Kitabatake (2011).

The statistics in Table 8 include all three ET pathways. Removing direct ETs, which have a transition period of $0 \mathrm{~h}$, the mean transition period in each basin typically increases by about 5-10 h. In the WNP and the NAT, $B \rightarrow V_{T}$ ETs take longer than those of type $V_{T} \rightarrow B$ (Table S1); the differences in ERA-Interim $(24 \mathrm{~h}$ in the NAT, $35 \mathrm{~h}$ in the WNP) are significant. There are no robust differences in the other basins.

\section{i. Cluster analysis}

Table 9 summarizes the outcome of the cluster analysis in each basin. Comprehensive basin-specific studies of TC clusters are given by Kossin et al. (2010) for the NAT, Camargo et al. (2007c) for the WNP, Camargo et al. (2008) for the ENP, and Ramsay et al. (2012) for the SH. Our numbering of the clusters matches that of these studies. Only the clusters with the highest numbers of ET storms (selected based on Fig. S4) are analyzed further in this section. Figure 15 shows all TC tracks in these clusters along with their mean regression curves.

The typical geographic trajectories of ET storms in the different clusters go along with distinct ET pathways through the CPS. The most salient examples are cluster 3 and cluster 5 in the WNP: In cluster $5,70 \%-80 \%$ of ET storms undergo a $B \rightarrow V_{T}$ transition (Table 9), maintaining their warm core over the warm waters of the Kuroshio Current while becoming increasingly asymmetric, until they complete ET at the margin of a strong shear zone near the coast of Japan (Fig. 16). In contrast, cluster 3 TCs complete ET over the open ocean and are more likely to undergo a $V_{T} \rightarrow B$ transition. Cluster $3 \mathrm{ET}$ storms begin their transition farther northeast, in an environment with cooler SSTs (Fig. 16). They typically take about half as long to complete ET as cluster 5 storms and are more prone to direct transitions, probably because they start out as weaker systems: More than $60 \%$ of cluster 5 TCs have hurricane strength $6 \mathrm{~h}$ prior to ET onset, but only about $40 \%$ of cluster 3 TCs (not shown).

In the NAT, cluster $3 \mathrm{TCs}-$ many of which are classical "Cape Verde" storms originating east of Africaundergo ET farther south and in a zone of higher SST than cluster 1 TCs. As in the WNP, ET storms in warmer waters more often take the $B \rightarrow V_{T}$ route, they are more intense at ET onset and have longer transition time periods. Cluster 1 TCs form mainly between June and November and have a constantly high ET fraction of about $80 \%$, whereas the ET fraction of cluster 3 TCs increases from July to a peak value of about $70 \%$ in late fall (not shown).

The majority of ET storms in the $\mathrm{SH}$ are members of cluster 6 (eastern AUS region) or cluster 7 (SP). Cluster 7 ETs, which more often take the $V_{T} \rightarrow B$ pathway, tend to occur farther poleward and take less time to complete. In general, the statistics of the ET storms in these clusters are similar to those already shown for the AUS region and the SP. In the ENP and the NI, there is less agreement between the two reanalysis datasets on the differences between clusters (Table 9).

\section{Summary}

This paper presents a global climatology of tropical cyclones (TCs) that undergo extratropical transition (ET) in the time period 1979-2017. The climatology is based on objective ET detection in the cyclone phase space (CPS), calculated from JRA-55 and ERA-Interim reanalysis data. 


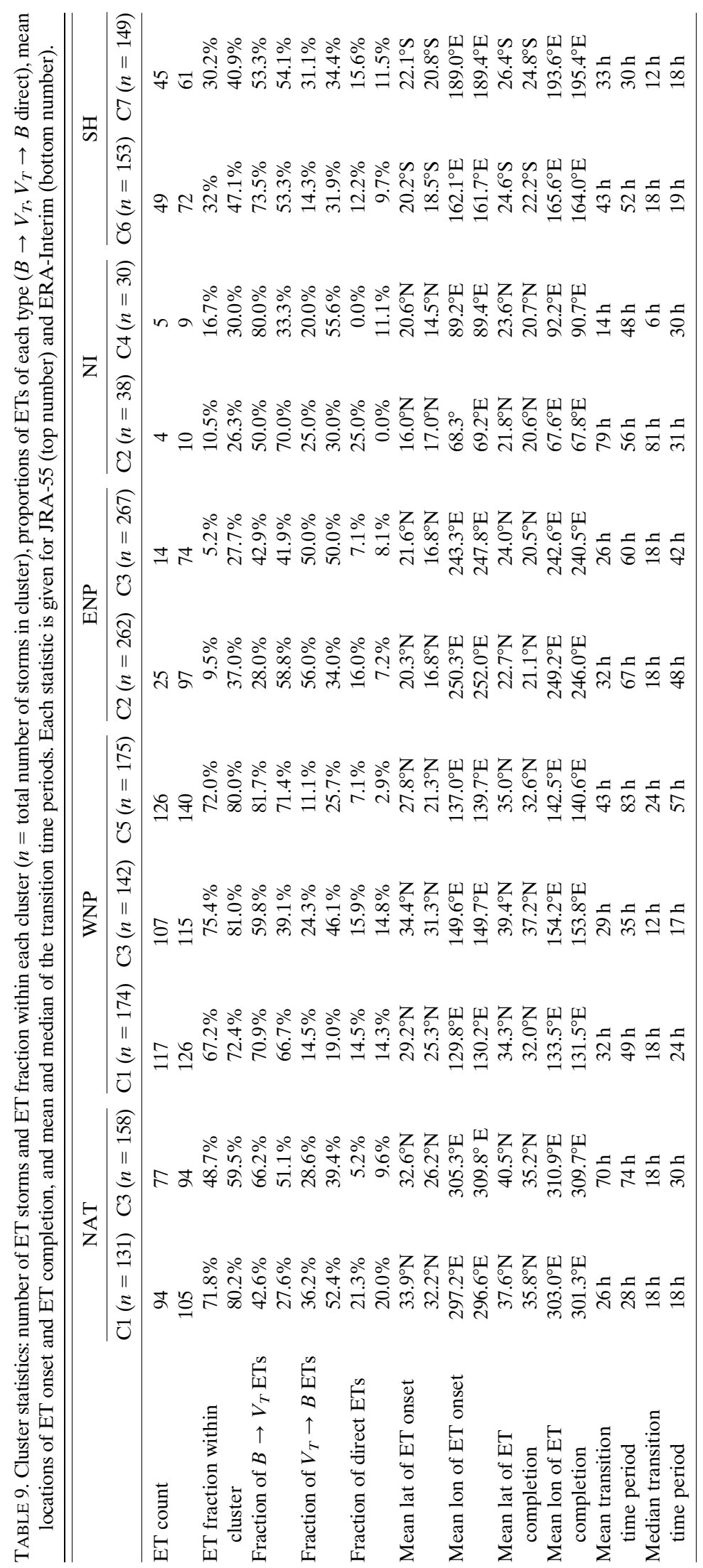



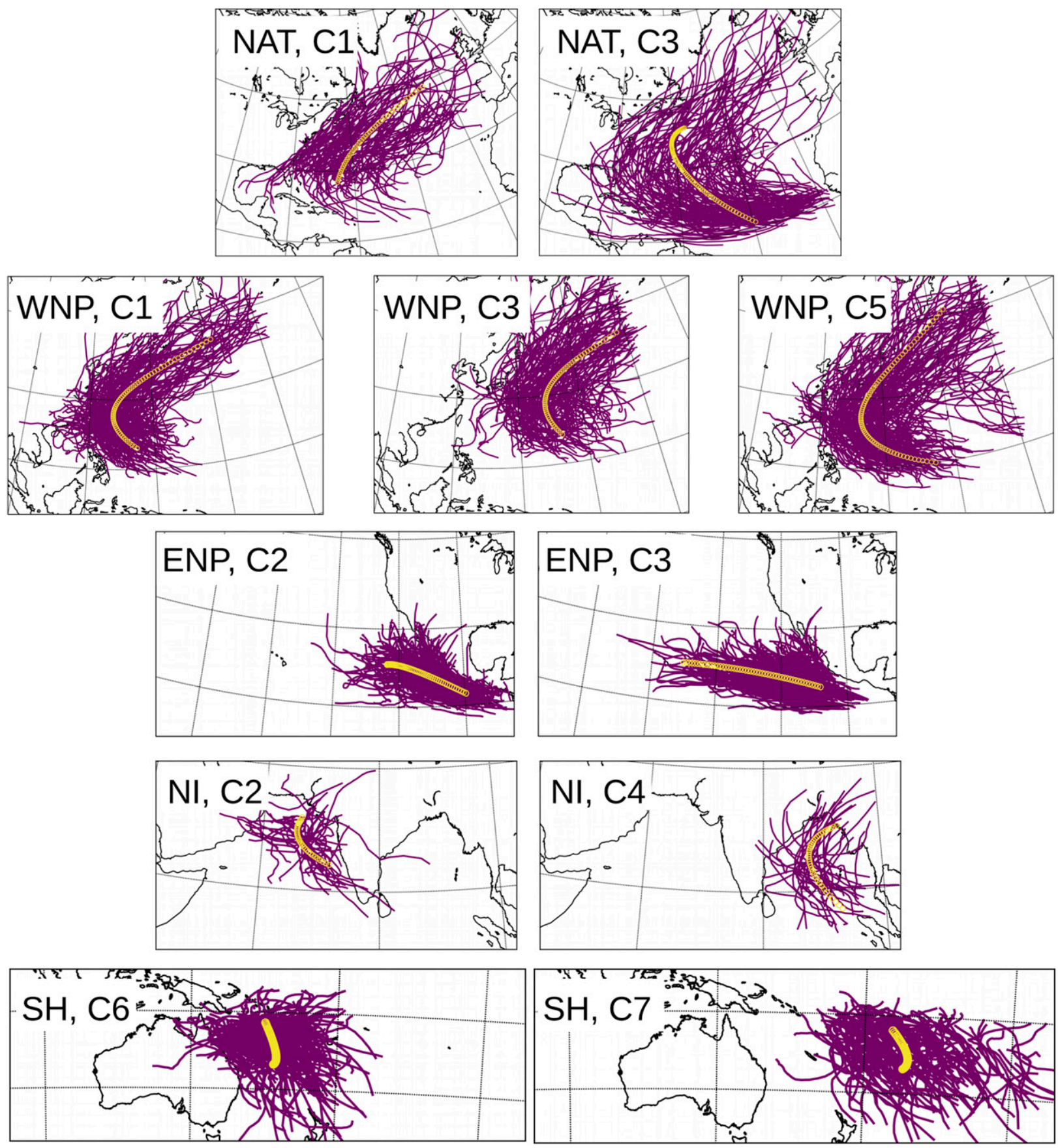

FIG. 15. Tracks of the TCs in clusters 1 and 3 in the NAT, in clusters 1,3 , and 5 in the WNP, in clusters 2 and 3 in the ENP, in clusters 2 and 4 in the NI, and in clusters 6 and 7 in the SH. The mean regression curve of each cluster is shown in open yellow circles.

Our findings can be summarized as follows:

- ET fractions vary substantially between the seven basins examined here: At the top end, about half of the storms in the North Atlantic, the western North Pacific and the South Pacific undergo ET. The south Indian Ocean and the Australian region have ET fractions of $20 \%-30 \%$. TCs rarely undergo ET in the north Indian Ocean and in the eastern North Pacific. In the north Indian Ocean, continental landmass stands in the way of northward moving storms, while a strong subtropical ridge over southwest North America generates a westward steering flow that prevents ET from occurring in the eastern North Pacific. 

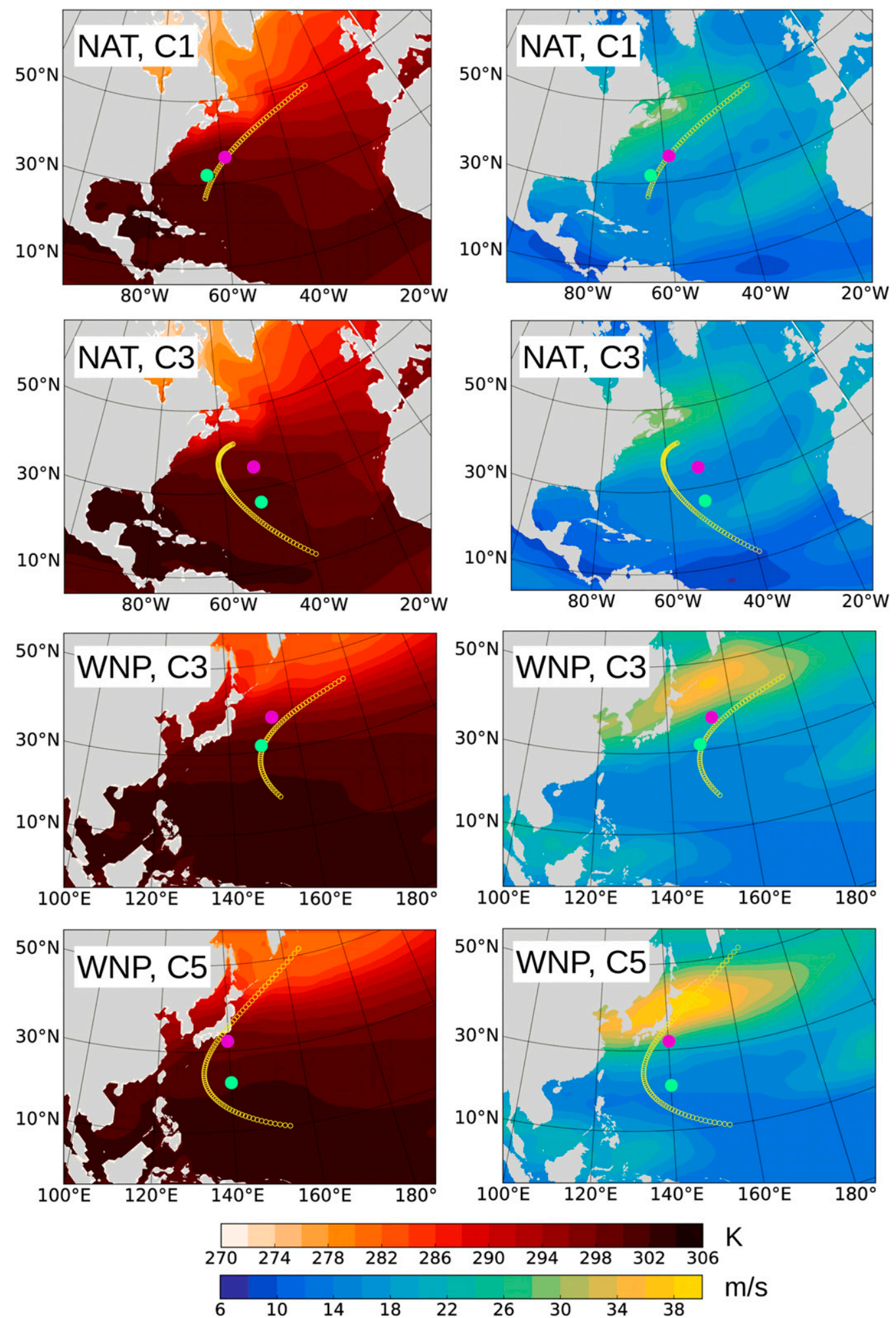

FIG. 16. (left) Composites of SST and (right) total vertical wind shear between 200 and $850 \mathrm{hPa}$ from ERAInterim, for the ET storms in clusters 1 and 3 in the NAT, and for those in clusters 3 and 5 in the WNP. The composites are based on the 6-hourly time steps between ET onset and ET completion of all ETs within each cluster (using the ERA-Interim classification). Also shown are the mean regression trajectory (open yellow circles) and the mean locations of ET onset (green dots) and ET completion (purple dots) for each cluster. 
- The majority of ETs are transformations that start with the TC becoming thermally asymmetric and end with the formation of a cold core. This type of ET is most common in the western North Pacific. However, a substantial fraction of ETs takes the reverse pathway, developing a cold core before becoming asymmetric. This pathway is found to be most common in the eastern North Pacific and the North Atlantic.

- Different ET pathways can be linked to different geographical trajectories and environmental settings. Over warmer sea surface temperatures, TCs undergoing ET tend to lose their thermal symmetry while still maintaining a warm core. These transitions usually take longer to complete than those starting with the loss of the warm core.

- Of all basins, coastal regions in the North Atlantic and the western North Pacific are most frequently affected by landfalling TCs that have started or completed ET. During the 1979-2017 period, such landfall events happen 3-4 times per year in the North Atlantic, 7-10 times per year in the western North Pacific, and once every 1-2 years in the Australian region.

- The choice of the reanalysis dataset used to calculate the CPS parameters has a substantial impact on the resulting climatology. ET fractions calculated in ERA-Interim exceed those calculated in JRA-55 (and also the ET observations archived in the best tracks), especially in the eastern North Pacific. In Part II, we examine these differences in more detail, by comparing the CPS-based identification of ET storms in JRA-55 and ERA-Interim to the ET storms defined in the best track datasets by human forecasters.

Acknowledgments. The authors thank Dr. Robert Hart for providing Grid Analysis and Display System (GrADS) scripts that facilitated the development of the Python code used in this study. The funding for this research was provided by NASA Cooperative Agreement NNX15AJ05A, and by NSF under Grant ATM-1322532. The authors also thank the following organizations for making the data used in this study available: ECMWF (ERA-Interim reanalysis data), JMA (JRA-55 reanalysis data and western North Pacific best track data), NHC (North Atlantic and eastern North Pacific best track data), and JTWC (western North Pacific, North Indian Ocean, and Southern Hemisphere best track data).

\section{REFERENCES}

Agustí-Panareda, A., S. L. Gray, G. C. Craig, and C. Thorncroft, 2005: The extratropical transition of tropical cyclone Lili (1996) and its crucial contribution to a moderate extratropical development. Mon. Wea. Rev., 133, 1562-1573, https://doi.org/ 10.1175/MWR2935.1.
Atallah, E. H., and L. F. Bosart, 2003: The extratropical transition and precipitation distribution of Hurricane Floyd (1999). Mon. Wea. Rev., 131, 1063-1081, https://doi.org/10.1175/15200493(2003)131<1063:TETAPD>2.0.CO;2.

Barnston, A. G., M. Chelliah, and S. B. Goldenberg, 1997: Documentation of a highly ENSO-related SST region in the equatorial Pacific: Research note. Atmos.-Ocean, 35, 367-383, https://doi.org/10.1080/07055900.1997.9649597.

Bell, G. D., and M. Chelliah, 2006: Leading tropical modes associated with interannual and multidecadal fluctuations in North Atlantic hurricane activity. J. Climate, 19, 590-612, https:// doi.org/10.1175/JCLI3659.1.

Bieli, M., S. J. Camargo, A. H. Sobel, J. L. Evans, and T. Hall, 2019: A global climatology of extratropical transition. Part II: Statistical performance of the cyclone phase space. J. Climate, 32, 3583-3597, https://doi.org/10.1175/JCLI-D-18-0052.1.

Boudreault, M., L.-P. Caron, and S. J. Camargo, 2017: Reanalysis of climate influences on Atlantic tropical cyclone activity using cluster analysis. J. Geophys. Res., 122, 4258-4280, https:// doi.org/10.1002/2016JD026103.

Brammer, A., and C. Thorncroft, 2017: Evaluation of reanalysis tropical cyclone structure with global Hawk 1 dropsonde observations. 29 pp., accessed May 2018, https://www.semanticscholar.org/paper/ Evaluation-of-Reanalysis-Tropical-Cyclone-Structure-BrammerThorncroft/27947cc7a2a5bb51ba78c0eccf4de34fead5d6bb.

Camargo, S. J., and A. H. Sobel, 2005: Western North Pacific tropical cyclone intensity and ENSO. J. Climate, 18, 29963006, https://doi.org/10.1175/JCLI3457.1.

$\longrightarrow$, K. A. Emanuel, and A. H. Sobel, 2007a: Use of a genesis potential index to diagnose ENSO effects on tropical cyclone genesis. J. Climate, 20, 4819-4834, https://doi.org/10.1175/JCLI4282.1.

— A. W. Robertson, S. J. Gaffney, P. Smyth, and M. Ghil, 2007b: Cluster analysis of typhoon tracks. Part I: General properties. J. Climate, 20, 3635-3653, https://doi.org/10.1175/JCLI4188.1.

,,,,---- and,$- 2007 \mathrm{c}$ : Cluster analysis of typhoon tracks. Part II: Large-scale circulation and ENSO. J. Climate, 20, 3654-3676, https://doi.org/10.1175/JCLI4203.1.

,-- A. G. Barnston, and M. Ghil, 2008: Clustering of eastern North Pacific tropical cyclone tracks: ENSO and MJO effects. Geochem. Geophys. Geosyst., 9, Q06V05, https:// doi.org/10.1029/2007GC001861.

Chia, H. H., and C. Ropelewski, 2002: The interannual variability in the genesis location of tropical cyclones in the northwest Pacific. J. Climate, 15, 2934-2944, https://doi.org/10.1175/15200442(2002)015<2934:TIVITG >2.0.CO;2.

Chiang, J., and D. Vimont, 2004: Analogous Pacific and Atlantic meridional modes of tropical atmosphere-ocean variability. J. Climate, 17, 4143-4158, https://doi.org/10.1175/JCLI4953.1.

CPC, 2018: Climate Prediction Center monthly atmospheric and SSI indices. CPC, accessed July 2018, http://www.cpc.ncep.noaa.gov/ data/indices/.

Dee, D. P., and Coauthors, 2011: The ERA-Interim reanalysis: Configuration and performance of the data assimilation system. Quart. J. Roy. Meteor. Soc., 137, 553-597, https://doi.org/10.1002/qj.828.

Ebita, A., and Coauthors, 2011: The Japanese 55-year reanalysis "JRA-55": An interim report. SOLA, 7, 149-152, https:/ doi.org/10.2151/sola.2011-038

Emanuel, K. A., 1988: The maximum intensity of hurricanes. J. Atmos. Sci., 45, 1143-1155, https://doi.org/10.1175/15200469(1988)045<1143:TMIOH > 2.0.CO;2.

— S. Ravela, E. Vivant, and C. Risi, 2006: A statistical deterministic approach to hurricane risk assessment. Bull. Amer. Meteor. Soc., 87, 299-314, https://doi.org/10.1175/BAMS-87-3-299. 
Evans, C., and Coauthors, 2017: The extratropical transition of tropical cyclones. Part I: Cyclone evolution and direct impacts. Mon. Wea. Rev., 145, 4317-4344, https://doi.org/10.1175/ MWR-D-17-0027.1.

Evans, J. L., and R. E. Hart, 2003: Objective indicators of the life cycle evolution of extratropical transition for Atlantic tropical cyclones. Mon. Wea. Rev., 131, 909-925, https://doi.org/ 10.1175/1520-0493(2003)131<0909:OIOTLC $>2.0 . C O ; 2$

Foley, G. R., and B. N. Hanstrum, 1994: The capture of tropical cyclones by cold fronts off the west coast of Australia. Wea. Forecasting, 9, 577-592, https://doi.org/10.1175/15200434(1994)009<0577:TCOTCB > 2.0.CO;2.

Frank, W. M., and G. S. Young, 2007: The interannual variability of tropical cyclones. Mon. Wea. Rev., 135, 3587-3598, https:// doi.org/10.1175/MWR3435.1.

Gaffney, S., 2004: Probabilistic curve-aligned clustering and prediction with regression mixture models. Ph.D. thesis, University of California, $281 \mathrm{pp}$

_ A. W. Robertson, P. Smyth, S. J. Camargo, and M. Ghil, 2007: Probabilistic clustering of extratropical cyclones using regression mixture models. Climate Dyn., 29, 423-440, https:// doi.org/10.1007/s00382-007-0235-z.

Gray, W. M., 1984: Atlantic seasonal hurricane frequency. Part I: El Niño and $30 \mathrm{mb}$ quasi-biennial oscillation influences. Mon. Wea. Rev., 112, 1649-1668, https://doi.org/10.1175/15200493(1984)112<1649:ASHFPI >2.0.CO;2.

Griffin, K. S., and L. F. Bosart, 2014: The extratropical transition of tropical cyclone Edisoana (1990). Mon. Wea. Rev., 142, 2772 2793, https://doi.org/10.1175/MWR-D-13-00282.1.

Hart, R. E., 2003: A cyclone phase space derived from thermal wind and thermal asymmetry. Mon. Wea. Rev., 131, 585-616, https://doi.org/10.1175/1520-0493(2003)131<0585: ACPSDF $>2.0 . \mathrm{CO} ; 2$.

- , and J. L. Evans, 2001: A climatology of the extratropical transition of Atlantic tropical cyclones. J. Climate, 14, 546-564, https://doi.org/10.1175/1520-0442(2001)014<0546: ACOTET $>2.0 . \mathrm{CO} ; 2$.

Hatsushika, H., J. Tsutsui, M. Fiorino, and K. Onogi, 2006: Impact of wind profile retrievals on the analysis of tropical cyclones in the JRA-25 reanalysis. J. Meteor. Soc. Japan, 84, 891-905, https://doi.org/10.2151/jmsj.84.891.

Hoskins, B. J., and P. J. Valdes, 1990: On the existence of stormtracks. J. Atmos. Sci., 47, 1854-1864, https://doi.org/10.1175/ 1520-0469(1990)047<1854:OTEOST>2.0.CO;2.

Jones, S. C., and Coauthors, 2003: The extratropical transition of tropical cyclones: Forecast challenges, current understanding, and future directions. Wea. Forecasting, 18, 10521092, https://doi.org/10.1175/1520-0434(2003)018<1052: TETOTC $>2.0 . \mathrm{CO} ; 2$.

Kim, H.-M., P. J. Webster, and J. A. Curry, 2009: Impact of shifting patterns of Pacific Ocean warming on North Atlantic tropical cyclones. Science, 325, 77-80, https://doi.org/10.1126/ science. 1174062.

,-- , and -2011 : Modulation of North Pacific tropical cyclone activity by three phases of ENSO. J. Climate, 24, 18391849, https://doi.org/10.1175/2010JCLI3939.1.

Kitabatake, N., 2011: Climatology of extratropical transition of tropical cyclones in the western North Pacific defined by using cyclone phase space. J. Meteor. Soc. Japan, 89, 309-325, https://doi.org/10.2151/jmsj.2011-402.

Klein, P. M., P. A. Harr, and R. L. Elsberry, 2000: Extratropical transition of western North Pacific tropical cyclones: An overview and conceptual model of the transformation stage.
Wea. Forecasting, 15, 373-395, https://doi.org/10.1175/15200434(2000)015<0373:ETOWNP > 2.0.CO;2.

Kobayashi, S., and Coauthors, 2015: The JRA-55 reanalysis: General specifications and basic characteristics. J. Meteor. Soc. Japan, 93, 5-48, https://doi.org/10.2151/jmsj.2015-001.

Kossin, J. P., S. J. Camargo, and M. Sitkowski, 2010: Climate modulation of North Atlantic hurricane tracks. J. Climate, 23, 3057-3076, https://doi.org/10.1175/2010JCLI3497.1.

Krishnamurti, T., L. Stefanova, and V. Misra, 2013: Tropical Meteorology: An Introduction. Springer, $424 \mathrm{pp}$.

Liu, M., G. A. Vecchi, J. A. Smith, and H. Murakami, 2017: The present-day simulation and twenty-first-century projection of the climatology of extratropical transition in the North Atlantic. J. Climate, 30, 2739-2756, https://doi.org/10.1175/ JCLI-D-16-0352.1.

Loridan, T., E. Scherer, M. Dixon, E. Bellone, and S. Khare, 2014: Cyclone wind field asymmetries during extratropical transition in the western North Pacific. J. Appl. Meteor. Climatol., 53, 421-428, https://doi.org/10.1175/JAMC-D-13-0257.1.

Masson, A., 2014: The extratropical transition of Hurricane Igor and the impacts on Newfoundland. Nat. Hazards, 72, 617-632, https://doi.org/10.1007/s11069-013-1027-x.

McTaggart-Cowan, R., J. R. Gyakum, and M. K. Yau, 2003: The influence of the downstream state on extratropical transition: Hurricane Earl (1998) case study. Mon. Wea. Rev., 131, 1910 1929, https://doi.org/10.1175//2589.1

Molinari, J., and D. Vollaro, 2013: What percentage of western North Pacific tropical cyclones form within the monsoon trough? Mon. Wea. Rev., 141, 499-505, https://doi.org/10.1175/ MWR-D-12-00165.1.

NOAA ESRL, 2018: Monthly climate timeseries. ESRL, accessed July 2018, https://www.esrl.noaa.gov/psd/data/timeseries/ monthly/.

Patricola, C. M., R. Saravanan, and P. Chang, 2017: A teleconnection between Atlantic sea surface temperature and eastern and central North Pacific tropical cyclones. Geophys. Res. Lett., 44, 1167-1174, https://doi.org/10.1002/2016GL071965.

Ramsay, H. A., S. J. Camargo, and D. Kim, 2012: Cluster analysis of tropical cyclone tracks in the Southern Hemisphere. Climate Dyn., 39, 897-917, https://doi.org/10.1007/s00382-011-1225-8.

Roseli, H., J. Prieto, I. Smiljanic, S. Lancaster, and J. Asmus, 2017: Hurricane Ophelia's transition. EUMETSAT, https://www. eumetsat.int/website/home/Images/ImageLibrary/DAT_3678625. html.

Schenkel, B. A., and R. E. Hart, 2012: An examination of tropical cyclone position, intensity, and intensity life cycle within atmospheric reanalysis datasets. J. Climate, 25, 3453-3475, https://doi.org/10.1175/2011JCLI4208.1.

Schiemann, R., D. Lüthi, and C. Schär, 2009: Seasonality and interannual variability of the westerly jet in the Tibetan Plateau region. J. Climate, 22, 2940-2957, https://doi.org/10.1175/2008JCLI2625.1.

Schreck, C. J., K. R. Knapp, and J. P. Kossin, 2014: The impact of best track discrepancies on global tropical cyclone climatologies using IBTrACS. Mon. Wea. Rev., 142, 3881-3899, https:// doi.org/10.1175/MWR-D-14-00021.1.

Sinclair, M. R., 2002: Extratropical transition of southwest Pacific tropical cyclones. Part I: Climatology and mean structure changes. Mon. Wea. Rev., 130, 590-609, https://doi.org/ 10.1175/1520-0493(2002)130<0590:ETOSPT>2.0.CO;2.

Song, J.-J., Y. Wang, and L. Wu, 2010: Trend discrepancies among three best track data sets of western North Pacific tropical cyclones. J. Geophys. Res., 115, D12128, https://doi.org/ 10.1029/2009JD013058. 
Sousounis, P., and M. Desflots, 2010: Evaluating the impacts of extratropical transitioning on typhoon losses via synoptic case studies. 29th Conf. on Hurricanes and Tropical Meteorology, Tucson, AZ, Amer. Meteor. Soc., P1.35, https://ams.confex.com/ ams/29Hurricanes/techprogram/paper_169228.htm.

Studholme, J., K. Hodges, and C. Brierley, 2015: Objective determination of the extratropical transition of tropical cyclones in the Northern Hemisphere. Tellus, 67A, 24474, https:// doi.org/10.3402/tellusa.v67.24474.

Thorncroft, C., and S. C. Jones, 2000: The extratropical transitions of Hurricanes Felix and Iris in 1995. Mon. Wea. Rev., 128, 947-972, https://doi.org/10.1175/1520-0493(2000)128<0947: TETOHF $>2.0 . \mathrm{CO} ; 2$.

Vimont, D. J., and J. P. Kossin, 2007: The Atlantic meridional mode and hurricane activity. Geophys. Res. Lett., 34, L07709, https://doi.org/10.1029/2007GL029683.

Wang, B., and J. C. L. Chan, 2002: How strong ENSO events affect tropical storm activity over the western North Pacific. J. Climate, 15, 1643-1658, https://doi.org/10.1175/15200442(2002)015<1643:HSEEAT > 2.0.CO;2.

Wessel, P., and W. H. Smith, 1996: A global, self-consistent, hierarchical, high-resolution shoreline database. J. Geophys. Res., 101, 8741-8743, https://doi.org/10.1029/96JB00104.
Wood, K. M., and E. A. Ritchie, 2014: A 40-year climatology of extratropical transition in the eastern North Pacific. J. Climate, 27, 5999-6015, https://doi.org/10.1175/JCLI-D-13-00645.1.

Ying, M., E.-J. Cha, and H. J. Kwon, 2011: Comparison of three western North Pacific tropical cyclone best track datasets in a seasonal context. J. Meteor. Soc. Japan, 89, 211-224, https:// doi.org/10.2151/jmsj.2011-303.

Zarzycki, C. M., D. R. Thatcher, and C. Jablonowski, 2016: Objective tropical cyclone extratropical transition detection in highresolution reanalysis and climate model data. J. Adv. Model. Earth Syst., 9, 130-148, https://doi.org/10.1002/2016MS000775.

Zhang, W., G. A. Vecchi, H. Murakami, G. Villarini, and L. Jia, 2016: The Pacific meridional mode and the occurrence of tropical cyclones in the western North Pacific. J. Climate, 29, 381-398, https://doi.org/10.1175/JCLI-D-15-0282.1.

, G. Villarini, H. Murakami, A. Rosati, X. Yang, L. Jia, and F. Zeng, 2017: Modulation of western North Pacific tropical cyclone activity by the Atlantic meridional mode. Climate Dyn., 48, 631-647, https://doi.org/10.1007/s00382-0163099-2.

Zhu, Y., 2003: Large-Scale Inhomogeneous Thermodynamics and Application for Atmospheric Energetics. Cambridge International Science Publishing, 634 pp. 